\title{
The "Research Jury Method": The Application of the Jury Trial Model to Evaluating the Validity of Descriptive and Causal Statements about Psychotherapy Process and Outcome
}

\author{
ARTHUR C. BOHART ${ }^{\text {a,e }}$, KAREN L. TALLMAN ${ }^{\text {, }}$, \\ GAYLE BYOCK ${ }^{c}$, \& THOMAS MACKRILL ${ }^{d}$
}

a

$\mathrm{b}$

Kaiser Permanente, Oakland, California

C Saybrook University, San Francisco, CA

d Aarhus University, Aarhus, Denmark

e Correspondence concerning this article should be addressed to Arthur C. Bohart, Saybrook University, 747 Front St. 3rd Floor, San Francisco, CA 94111-1920.

Email: abohart@saybrook.edu

\begin{abstract}
A rationale for using a qualitative "Research Jury Method" for assessing psychotherapy outcome as an alternative to randomized controlled trials is given. It is argued that the jury research method is compatible with scientific practice and that science itself relies on the method. Methods and results from two preliminary studies are briefly summarized. In the current study three jurors evaluated a rich case history to decide (a) whether the client changed, and (b) to what degree, and how, psychotherapy contributed. Results suggest the method can be a useful way of assessing psychotherapy outcome and can produce differentiated insights into case-specific changes and change processes. A conclusion is that we can draw inferences and make plausible cases that people change in psychotherapy and that therapy contributes to it from individual cases using rich data, qualitative analysis, and a jury method. In addition, we can learn things from this method that one cannot learn as easily from randomized controlled trials.
\end{abstract}

Key words: Research Jury Method, adjudicated case study method, case law, psychotherapy process and outcome, case-specific changes, case studies, clinical case studies

The Research Jury Method (Bohart \& Humphreys, 2000; Humphreys, Bohart, \& Dutile, 2000) was originally developed as a qualitative, human science alternative to the randomized controlled trial (RCT). This was in response to the empirically supported treatments movement (Task Force, 1995), which, although allowing case study evidence, privileged a view of psychotherapy and research methodology that was not in accord with how many therapists of humanistic, experiential, constructivistic, strategic, and psychodynamic traditions viewed research and practice (e.g., Bohart, O’Hara, and Leitner, 1998; Division 32 Task Force, 2004). 
Traditionally, psychotherapy researchers have identifed the randomized controlled trial (RCT) as the "gold standard." The RCT is based on the model of the experiment, in which a tightly controlled independent variable is systematically varied to see if the dependent variable varies along with it. If it does, then it can be said that the independent variable "caused" whatever happened with the dependent variable. In this model the independent variable is related in a linear causal fashion to the dependent variable. In terms of psychotherapy, the use of the RCT is patterned after drug trials, in which it is assumed that the "independent variable" (the drug or psychotherapy) can be manipulated or varied, and its effects on the dependent variable (the disorder) assessed. It can then be said that the drug or psychotherapy "caused" changes in the dependent variable (depression, anxiety, etc.).

The drug trial model is only a loose metaphor when applied to psychotherapies that rely on interactive dialogue and that do not primarily see themselves as "treatments" for disorders, such as person-centered psychotherapy. Indeed, questions have recently been raised as to whether this model is appropriate for any approach to psychotherapy. Psychotherapy is a complex interactional process, where the "dependent variable" (the client) is an active generative being who contributes to the process, and where therefore there is no true "independent variable" (see, for instance, Krause \& Lutz, 2009; Stiles, 2009). Further, the RCT drug trial research model destroys naturally occurring ecological connections-such as how the client chooses his or her therapist - that play a role in how psychotherapy operates in real life, making what is found a science of the possible but not necessarily of the probable or actual (Petrinovich, 1979).

We shall present the philosophical rationale for an alternative qualitative adjudicational model (the idea of adjudication originally came from Ron Miller, 1999) based on case history data. If one has sufficiently rich data on a particular psychotherapy case, we can use qualitative methods to plausibly establish (a) whether the person changed, and (b) if the therapy process contributed to the change. Causality in this model is not linear and mechanistic, but rather a form of "soft” or enabling causality (e.g., Elliott, 2002). Therapy does not mechanistically "cause” individuals to get better, but rather provides an occasion for them to mobilize their own resources for change. Adjudication means that the decision as to whether the client plausibly changed or not is made by a process similar to how juries arrive at decisions. In real life, jury decisions are given much weight as to truth value-juries arrive, for instance, at life and death decisions. We will also argue that all science is ultimately adjudicational.

There has been increasing use of qualitative methodology to study psychotherapy process. However, qualitative work on psychotherapy outcome has been limited. In this paper we present a rationale for studying outcome qualitatively, and then present the results from the application of our method to a case history.

\section{PHILOSOPHICAL RATIONALE}

Questions about whether psychotherapy works (outcome questions) boil down to two issues: (a) was there positive change, and (b) if so, did psychotherapy cause it? In order to assess these the randomized controlled trial (RCT) has traditionally been the method of choice. In its bare bones form, an ideal study compares a treatment to a placebo control group. Both are 
applied to randomly selected clients. Standardized measures of outcome are used. The first issue has to do with whether there has been "real" change as opposed to, for instance, clients (or therapists) just saying that change has occurred. This could be due to clients saying they changed out of enthusiasm for the process, out of some kind of halo effect, out of feelings of gratitude and a desire to please the therapist, or out of cognitive dissonance (e.g., "I invested all this effort; I must have changed"). The Consumer Reports study (Seligman, 1995) was criticized because the conclusion that clients had changed was based on two self-report questions (essentially: did therapy help and how was their life at the present moment). But there was no control group and so clients saying that therapy had helped might have represented nothing more than their satisfaction with the process. Had there been a placebo control group, had the scores of clients in "real" therapy on these questions been higher than the scores of those in the placebo control, we would have had more confidence that something "real” had happened.

The second issue has to do with the question: If change did occur, did psychotherapy cause it? The Consumer Reports study was also criticized because, without a control group, there was no way of knowing for sure if therapy was responsible. Perhaps life events, or history, or maturation caused the changes (see the Campbell \& Stanley, 1967, the classic book for all the possible threats to internal validity). Here again a placebo control group would have provided the answer: If the treatment group "beat" the placebo control group, then one could say that it was the treatment which was responsible for the change, and not just history, maturation, nonspecific placebo effects, or other factors.

A qualitative perspective on outcome, however, leads to a different perspective on what was wrong with the Consumer Reports (CR) study and suggests an alternative to the RCT (Bohart \& Boyd, 1997a). From a qualitative perspective what was wrong with the Consumer Reports study was not that it was not an RCT, but that it only gathered data with five- or sixpoint rating scales. For instance, on the item "How much did treatment help with the specific problem that led you to therapy," the client might circle "made things a lot better" (Seligman, 1995, pp. 967-968). How are we to judge whether the client is just saying that, or if, in fact, the client did get better? And how could we assess if psychotherapy contributed to feeling better? With such little detail from clients one has no basis upon which to judge the usefulness or reliability of clients' reports of how helpful therapy was. Using such a measuring scale, one is almost forced to use an RCT in order to assess how valid and reliable such reports are.

But suppose one had considerably more rich case history detail from the CR clients. Suppose one had tapes of all the therapy sessions. Or one had rich process notes from both therapist and client, or therapist and client diaries. Such data might allow one to assess with greater confidence the plausibility of the clients' accounts as to (a) whether they "really" changed or not, and (b) if so, how therapy contributed to that change. Furthermore, the conclusion could, in principle, be checked by an independent party against the case record (just like, to foreshadow our discussion of the research jury method, an appeals judge can check the jury's conclusions against the case record). One thing that was problematic with Freud's case studies was that there was no way to check Freud's conclusions. Freud believed he was being scientific because he believed he was developing his theories from observations in therapy. However there was nothing systematic about his method which either allowed us to have 
Validity of Descriptive and Causal Statements about Psychotherapy Process and Outcome

A.C. Bohart, K.L. Tallman, G. Byock, \& T. Mackrill

Pragmatic Case Studies in Psychotherapy, http://pcsp.libraries.rutgers.edu

Volume 7, Module 1, Article 8, pp. 101-144, 02-28-11 [copyright by authors]

confidence that his observations were based on unbiased data, or allowed us a way to check. Indeed, there are examples of how Freud's reports of the same case changed over time.

The current study is based on the argument that with a sufficiently rich case record, observers can plausibly draw conclusions as to whether a person changed in psychotherapy and if so whether therapy contributed to that change. In addition, a sufficiently rich case record will allow inferences to be drawn about what processes in therapy plausibly seemed to have helped, and what the complexities of the change process look like. Over time, with a sufficient number of cases, generalizations could be drawn about what is helpful in psychotherapy.

\section{Causality}

Our method is based on a "soft" view of causality rather than on a "hard" or efficientcausal view. A hard or efficient-causal view assumes that the goal of research is to establish a mechanistic, or linear causal relationship between the application of a technique and outcome, to demonstrate an if-and-only-if causal relationship. Science has been achieved when it can be shown that A causes B, in a billiard-ball deterministic way.

It is not clear that such models are appropriate for the complex human phenomenon which is psychotherapy. Many have argued that psychotherapy is a nonlinear, recursive, interactive process. Stiles (2009) has pointed out how both therapists and clients are continually adjusting to the emerging context of their interaction. Some of these adjustments are taking place at the macro level, where a therapist modifies his or her strategies based on how therapy is going. But at a much more suble micro level, therapist and client are continually interacting with one another and adjusting in ways that alter the flow of therapy no matter what the theoretical position espoused by the therapist. No two therapies are alike at a micro level. Therefore there really is no such thing as an independent variable that is being applied in the same way across clients. If this is the case, then the RCT is a crude instrument for the study of a subtle phenomenon.

Consider the typical RCT design in which a manualized version of the therapy being studied is applied to a "condition" (note: not a person). At best one has to pretend that a standardized treatment is being applied to a group of clients who share the same "condition." However many would argue that no matter how well manualized, some therapies such as psychodynamic and client-centered can be standardized in name only at a very high level of generality. The actual therapy process is a complex, nonlinear interactive one. This means that while there may be general formal similarities between two sessions of client-centered therapy, at a subtle level they will always be importantly different. For instance, while at a formal level the therapist can be said to be "warm," "empathic," and "nondirective," and to "use reflections," this is like arguing that two novels are the same because they both follow the rules of English grammar. The real "text" can vary enormously within those generalized formal confines, and the different "novels" of different interactions can unfold quite differently. It is a moot question whether the differences between the various enactments of client-centered therapy are more or less important than the abstract similarities. If it can be demonstrated that client-centered therapy, as defined by these formalized generalities "works," that tells us little about the subtleties of the process. In fact, if anything, it distorts it, because it makes it seem as if some 
kind of 'treatment' is being applied, with some kind of linear causal outcome popping out at the end, when in fact the complex trajectories of each individual therapy, all leading to the common "brute" outcome of change, are being missed. To say that client-centered therapy "caused" the outcome in a manner analogous to how radiation may "cause" cancer cells to die is misleading. It implies that client centered therapy works by creating a kind of domino effect, whereby the formal properties of the therapy cause a kind of linear mechanistic chain reaction leading to the outcome, when in fact the intervening process is much more likely described by complex recursive and interactive cycles of reciprocal causality.

\section{"Soft" Causality}

Our method is based on the idea of establishing a "soft" or plausible causal relationship between therapy factors and outcome rather than a strict or hard causal view. We believe this mirrors the actual change process in therapy, which is fundamentally probabilistic.

By a "soft causal" view of change in psychotherapy we mean that there may be no simple efficient-causal set of processes that constitute how psychotherapy works. Instead, therapy may be the "condition" or the "setting" which occasions change. However, it does not necessarily create or precipitate change in a linear causal way. An example is client centered therapy. From the standpoint of theory, client centered therapy helps by providing a warm, supportive context within which clients can come to feel safe and to explore themselves, giving them the space to instigate their own change processes. Therapy does not cause change in an efficient causal sense, but it does provide the context or the space within which it can occur. In this sense therapy is a place within which a complex interactive process can develop and range in a variety of ways with a variety of outcomes. Given a set of boundary conditions, a certain set or range of outcomes becomes more likely, and another set or range of outcomes becomes less likely. But all we can expect is an increase in probability of a certain range of outcomes. A roadway or channel provides a good metaphor. Within the boundaries of a roadway, different occupants will travel in different trajectories and at different speeds. We could not however say that the roadway "caused" certain kinds of driving behavior in any strict linear causal way. To the extent that we could say that the roadway "caused" the driver's behavior, we would have to take that to mean that it constrained it, promoted it, or influenced it. This is how we see causality in therapy.

Utilizing a soft view of causality from our qualitative research point of view, the question is: Can a plausible relationship be demonstrated between an experience in therapy and outcome, even if a strict linear causal path cannot be traced? Can such a relationship be demonstrated such that one can see how therapy could lead to such an outcome, although it cannot be demonstrated that therapy must lead to such an outcome (i.e., strict linear billiard ball causality)? Put another way, does therapy provide a set of conditions which increase the probability of certain outcomes?

Ideally, with sufficiently rich data, we might be able to develop a plausible and logical analysis of how therapy unfolded. For instance, if, in the best possible research scenario, we had client reports on what was happening in their lives outside of therapy (in the form of diaries), as well as tape recordings of all the therapy sessions, we might be able to develop plausible narratives tracing the complex interactive sequences between therapist and client, and client and 
Validity of Descriptive and Causal Statements about Psychotherapy Process and Outcome

A.C. Bohart, K.L. Tallman, G. Byock, \& T. Mackrill

Pragmatic Case Studies in Psychotherapy, http://pcsp.libraries.rutgers.edu

Volume 7, Module 1, Article 8, pp. 101-144, 02-28-11 [copyright by authors]

his or her life, that appeared to lead to changes. Replicated over a number of clients, we might then be able to look for commonalities across clients and develop some principles about how the process of change in therapy occurs.

In such a research methodology it becomes more interesting to study the individual trajectories by which individuals “occupy the space” of client-centered therapy (or some other therapy approach) and engage in that complex interactive process, and subsequently come to the outcomes they achieve, than it is to try to "manipulate the variables" in order to establish strict linear causal relationships. Of most importance in this day and age of accountability, we should be able to make a plausible argument that therapy can help individuals change for the better without the use of RCT designs.

Analysis of a whole set of therapies over time would let us map out the range of possibilities, and some of the more likely trajectories, as well as the kinds of choices and "interventions" which are more likely to make certain paths happen than other paths. But we do this not by invoking an a priori randomized controlled trial. Through this observation of naturally occurring variation, we are able to close in on more rather than less likely sequences. This means, that in a qualitative sense, no one study would definitively answer the question of causality, as the RCT presumes to do (although we all know it cannot). Rather, a whole collection of studies over time would lead to greater and greater confidence in the maps being developed.

\section{The Research Jury}

How do we decide upon a plausible set of interpretations of a given case, in particular the key interpretation of whether therapy helped or not. We use the metaphor of the jury trial. As in a jury trial, we have a set of jurors examine the evidence and draw conclusions. If individuals keep track of the evidence that forms the basis for their decisions, then they can make plausible arguments for their decisions. In the case of psychotherapy we expect that given a sufficiently complete record of a therapy case that it is in principle possible that a set of individuals can examine this record and reach a reasonable conclusion as to whether a) the person changed for the better or not, and b) to what extent therapy contributed to that change process.

The idea of the research jury came from Ron Miller (1999). Miller used the metaphor of "case law"- -how in the legal system certain cases can be used to establish principles of law. Although we use the jury metaphor, we do not specifically employ the metaphor of case law. For us, the method is called the "research jury method" because it is analogous to how a jury proceeds or adjudicates a case. Jurors have a case record which includes the evidence that was presented, along with prosecution and defense attorney arguments. The evidence may consist of eyewitness testimony, contracts, photographs, fingerprints, other laboratory evidence, testimony of others involved, testimony of antagonists and protagonists, expert witness testimony, and so on. Jurors keep track of the evidence and then at the end, weigh and evaluate it to come to a conclusion. The conclusion is supposed to be evidence-based, as are decisions in science. It is assumed that some degree of "truth" can be arrived at, and arrived at sufficiently that life and death decisions are based on the process. In general, this is true of juries with a reasonable degree of reliability (Burns, 2001). 
Is the jury method scientific? The answer is that adjudication plays a key role in the scientific process. In fact, science is ultimately adjudicational at heart. While data plays a major role in scientific decisions as to truth, ultimately a process similar to that of a jury is what actually decides what is accepted as a scientific conclusion. There is no simple relationship between data and conclusion, such that it can be calculated in a mechanistic fashion without a human judge involved.

In trials a distinction is drawn between "evidence" and "fact." Evidence is what is presented; "fact" is a conclusion drawn by a jury from an examination of the evidence. "Facts" are determined by the jury's decision as to the plausibility of the evidence. The same thing happens in science. Evidence is the research study and its findings. Whether it is accepted as a "fact" or not is based on an adjudication process.

The adjudication process is seen most clearly in journal peer-review. Whether a finding is translated from "evidence" to "fact" depends first on this process. As with juries, different reviewers often have different opinions as to the reliability and validity of the evidence. They may weigh design flaws differently. They may make different decisions on how compelling the evidence is. This is ultimately a process of human judgment and is not itself "data driven," because it is a process which operates on data to determine what data is to be considered as data. It is a complex process which involves all the intricacies of human judgment.

Different journals have different decision policies for acceptance. Some rely on unanimity among reviewers. Others may accept an article even if there is not unanimity. In all cases the editor functions as the "judge" who weighs the opinions of the different jurors and adjudicates the process him or herself, deciding either "publish,” "revise,” or "reject.” This judge is often confronted by reviews that may see the merits and the flaws of the study differently. The judge has to weigh the pro's and con's of the different judgments to arrive at a conclusion.

After a study is published, the adjudication process continues. Opponents of the study's findings can usually find some way of arguing that the conclusion that this is "fact" is unwarranted (see, for instance, the debate back and forth about evidence in a volume on evidence-based practice, Norcross, Levant, \& Beutler, 2006). Ultimately it becomes a matter of scientific opinion as to whether a conclusion is accepted as "fact" or not. Typically something ascends to the status of "fact" when a sufficiently large majority of the scientific community finds the evidence compelling enough to decide to accept it as "fact." Two examples in psychology are the conclusion that violence on television causes violent behavior and the conclusion that schizophrenia is primarily a biological disorder requiring drug treatment. These conclusions are accepted as fact by most psychologists and treated as such by textbooks. Yet there still exists minority opinion that neither of these conclusions is warranted based on the evidence (for violence and television, see Freedman, 2002; for schizophrenia, see Read, Mosher, \& Bentall, 2004). Even in physics, where majority opinion has long accepted quantum mechanics, there has existed minority opinion that Newtonian explanations are better.

Examples of "juries" in science are the various commissions that review evidence and draw conclusions, such as commissions that have concluded that global warming is real. Another example is when teams of investigators are commissioned to review the evidence in a particuar 
Validity of Descriptive and Causal Statements about Psychotherapy Process and Outcome

A.C. Bohart, K.L. Tallman, G. Byock, \& T. Mackrill

Pragmatic Case Studies in Psychotherapy, http://pcsp.libraries.rutgers.edu

Volume 7, Module 1, Article 8, pp. 101-144, 02-28-11 [copyright by authors]

area and draw conclusions. For instance, the Association for Psychological Science publishes periodic reviews of the literature in their series Psychological Science In The Public Interest. One example is a report by Anderson et al. (2003) looking at the effects of media violence on violent behavior in youth and concluding that media violence does cause violent behavior.

It is of interest that juries in the legal system may actually be selected more rigorously than juries in science. In the legal system prospective jurors are selected in a process where they are challenged by defense and prosecution lawyers. This is not the case with scientific juries. For instance, with the Anderson et al. (2003) review of the literature on media violence, the first four authors all have been explicitly identified with a stance that media violence causes violent behavior. No matter how hard such individuals may try to be objective, one wonders if juries like these can be said to truly be objective. Westen and Weinberger (2004) have noted that they could predict with a probability of one a commentator's response to a literature review on the Rorschach by knowing the commentator's prior views on the validity of the Rorschach. And this is of individuals supposedly objectively evaluating the evidence.

Finally, a key part of the adjudication process in science is making judgments based on a convergence of evidence. It has often been observed that no study is perfect. Instead, decisions are arrived at based on the degree to which a sufficiently large body of evidence converges to a conclusion, again similar to how a jury operates. This is how Darwinian theory is supported (Rozin, 2001; Shermer, 2006). As Rozin (2001) has noted, much of the evidence supporting Darwinian theory would have never gotten published in The Journal of Personality and Social Psychology. Yet, because there is so much evidence, from so many different sources, with different sources of error, that converge, Darwinian theory is supported. Jurors, too, adjudicate different sources of evidence, often imperfect, to reach a conclusion.

In sum, scientific decisions are ultimately never data-driven although they should be data-informed. What is to be considered data is itself an adjudicated decision process, as are conclusions as to what the data means or implies. Ultimately, decisions in science, as in jury decisions, are based on plausibility and argument, constrained by evidence.

We want to add a caveat. We are not agreeing with some postmodernists who have argued that there is nothing special about science as a way of knowing. Science is a particularly useful way of knowing. It is (or should be) a careful, transparent process of checking ideas and conclusions against data. It currently includes specialized methods for collecting and analyzing data that add greatly to its capacity for detecting subtle relationships. It therefore has increased odds of leading to the drawing of reliable conclusions, and has demonstrated over the years its power for discovering and confirming many facts about the nature of reality. Nonetheless, as with all forms of human knowing, human judgment plays a key role.

\section{PREVIOUS STUDIES UTILIZING THE ADJUDICATION METHOD}

Two previous studies were done exploring the viability of the research jury method using qualitative data. Jurors were to evaluate the available evidence and draw conclusions as to (a) whether the client changed, and (b) whether therapy contributed to the change. In addition they 
Validity of Descriptive and Causal Statements about Psychotherapy Process and Outcome

A.C. Bohart, K.L. Tallman, G. Byock, \& T. Mackrill

Pragmatic Case Studies in Psychotherapy, http://pcsp.libraries.rutgers.edu

Volume 7, Module 1, Article 8, pp. 101-144, 02-28-11 [copyright by authors]

tried to rule out (a) the hypothesis that the client had merely said he or she had changed in a posttherapy interview, and (b) that change could be due exclusively to extra-therapeutic factors.

\section{Study One}

The first study was done before we had actually conceived of what we were doing as an adjudicational method. This study, by Bohart and Boyd (1997a, 1997b), was of three sessions of psychotherapy. The clients and therapists were graduate students in a Marriage and Family Therapy program. They could be thought of as "participant-observers" because they were themselves graduate students training to be therapists. At the end of each of the three sessions clients filled out questionnaires in which they rated their experience of that session and of the therapist in that session. Additionally, they answered open-ended questionnaires about how they had utilized the therapy experience during the weeks between sessions. Then a week after the third session was over they reviewed their own data, and filled out an open-ended questionnaire where they were asked about how helpful the therapy had been, and how it had been helpful.

The two authors (the two "jurors") independently conducted analyses of the questionnaires. They looked for plausible evidence that clients had changed and that those changes were associated with their therapy experiences. This was demonstrated by finding evidence that:

- Clients had themselves noted that therapy helped.

- Outcomes were relatively specific and idiosyncratic to each client and varied from client to client.

- In their reports, clients were discriminating about how much therapy had helped, i.e., they did not in general give unabashedly positive testimonials.

- Clients were relatively specific about how therapy had helped.

- They provided supporting detail.

- They described plausible links to the therapy experience.

- They mentioned things that make it clear that clients either did something or experienced something different than what they normally do or experience in the course of their everyday lives.

- They mentioned things that didn't help.

The two authors found that they were able to develop plausible accounts for each of the clients indicating the specific kinds and degrees of changes they had undergone. Clients' accounts also let them make assessments of the likelihood that something about therapy had helped them change. They had also asked the clients to rate the degree of change they had experienced on the scales used in the Consumer Reports study. They found good agreement 
Validity of Descriptive and Causal Statements about Psychotherapy Process and Outcome

A.C. Bohart, K.L. Tallman, G. Byock, \& T. Mackrill

Pragmatic Case Studies in Psychotherapy, http://pcsp.libraries.rutgers.edu

Volume 7, Module 1, Article 8, pp. 101-144, 02-28-11 [copyright by authors]

between the qualitative analyses of outcome and clients' ratings on these scales. They also found that their independent assessments generally converged to the same conclusions.

An example of a narrative on client number 02 is as follows:

- 02 noted that therapy helped and the changes were specific and idiosyncratic to her (helped her to express feelings, focus on own feelings and be less co-dependent, and be more of an active participant);

- 02 was discriminating about how much it helped (“halfway towards resolution”);

- 02 was specific about how therapy helped (e.g., empty chair helped her practice expressing feelings which she then generalized to everyday life; therapy helped her take a more active role; therapist helped her focus on her feelings more than on others' feelings [reducing co-dependency];

- 02 provided supporting detail (e.g., it was helpful to have a neutral listener free of any background knowledge of the situation) and plausible links were described between outcome and the therapy experience (see above on empty chair);

- 02 mentioned things which indicated that therapy made something different happen ("realized I need to focus more on my feelings," and "empty chair helped me practice expressing feelings which I then used in everyday life"); and

- 02 did not mention anything that did not help.

In sum, it seems quite plausible that this client was benefited by her therapy experience.

\section{Study Two.}

A problem with Study One was that the data base for making judgments on the effectiveness of therapy was limited. Conclusions were based only on clients' questionnaires. Study Two (Bohart \& Humphreys, 2000; Humphreys et al., 2000) was specifically conceived of as a study of the research jury method and conclusions were to be based on a more elaborate case record. Five graduate student therapists worked with five undergraduate volunteer clients for up to eight sessions. All sessions of the therapy were taped, as was a pre-therapy intake interview, and a post-therapy interview where the client evaluated his or her therapy experience (with an interviewer who was not the therapist). As part of the logic of the study, clients were informed of the purpose of the study and enlisted as participant-observers from the start. They were told that the purpose was to develop criteria for deciding whether therapy had helped or not, and that their observations were valuable. They were told that learning how to identify if therapy did not help was just as important to us as when it did help.

After all sessions were taped, 6 graduate and undergraduate student “jurors” listened to the whole "case record" of a given individual, from intake through all sessions to exit interview. They were instructed to take intensive notes (in fact they were asked to transcribe major portions of each session), and then to reach a decision as to whether they thought the person had benefited 
from therapy, and if so how. They were asked to document the evidence for their decision. They were given a lengthy list of possible criteria to be used in reaching their decisions (see Appendix 1). However they were told that they did not need to use those criteria, and if they observed other criteria to make notes on what they were.

It was found that consensus could be reached, and that plausible cases could be made on whether individuals had or had not changed, and whether the changes were due to therapy or not. As an example, in one case, although the client reported that she had changed, the jury concluded that the change she had experienced was due to a change in circumstances in her life. Other issues addressed in therapy had not changed, leading to the conclusion that therapy had not helped her.

\section{THE CURRENT STUDY}

In the current study we had three jurors (co-authors Bohart, Tallman, and Byock). Arthur Bohart, $\mathrm{PhD}$, is a Professor of Psychology. Karen Tallman, $\mathrm{PhD}$, is a researcher at Kaiser Permanente, a health maintenance organization. Gayle Byock has a Master's degree in clinical psychology and is currently a college instructor. The case was contributed by Thomas Mackrill (2008) from his unpublished doctoral dissertation, and is published in this issue of the PCSP journal (Mackrill, 2011b), along with an epistemological, theoretical, and methodological introduction to the case and its context (Mackrill, 2011a).

Mackrill had clients and therapists keep diaries for 12-session therapies. Clients were seen at a clinic for adult children of alcoholics. Therapy was humanistic and existential in nature. Instead of listening to tapes of all 12 sessions and reading the diaries, we used as our "sufficiently rich case record" the intensive write up of one of Mackrill's case studies based on his data, namely, the case of client "Jane" and therapist "Joe" (Mackrill, 2011b). This case writeup consisted of data from the diaries of the therapist and client, and from tapes of the sessions. In the first few pages Mackrill identifies the concepts he utilized in organizing the data. These are based on a contextual view of behavior. In order to understand change in therapy one must look at the client's behavior and experiences across life contexts (Dreier, 2008). Specific organizing concepts utilized in writing up the case included focusing on the client's point of view in different contexts; the difference among points of view of the participants; and identifying shifts in perspective when they occurred. The write-up steered clear of an analysis in terms of theoretical mechanisms of change based on any particular theory of psychotherapy, such as cognitive-behavioral, existential, or psychodynamic. Advantages of Mackrill's write up were:

1) his focus on a cross-contextual view of psychotherapy. This led, through the client's diaries, to more data being provided on the client's role in therapy, both inside and outside of therapy. This point of view could have biased his case write up, but if it did it would have been against the hypothesis that therapy contributed to change. As it was it gave data on how extra-therapeutic factors might contribute to change.

2) Mackrill was not focused on outcome. He drew no clearcut conclusions on outcome. 
3) The case was written up primarily from the client's point of view, in contrast to the usual "therapist-centric" way of writing up cases.

4) Overall Mackrill stuck fairly close to reporting from the case record. When Mackrill did draw inferences, he was careful in identifying them and in giving evidence for them.

5) He included a good deal of quotes from the client and the therapist.

6) The case involved a triangulation of data: client's diary, therapist's diary, and tapes of therapy sessions.

7) It was sufficiently rich: 42 single spaced pages.

8) It was reviewed by both client and therapist who said it was accurate from their perspectives.

The client, Jane, reported headaches that had not been helped by medical treatment, a somatic stomach, an alcoholic mother, an abusive past, intrusive memories of trauma that she wanted to "forgive and forget," pervasive sadness, feeling that there was something fundamentally wrong with her, and relationship problems with men. These last included that she tried too hard to please men and in so doing lost herself.

Each of the three jurors was given the list of criteria used in the Bohart et al. (2000) study but told they need not use those critieria to reach conclusions if other criteria presented themselves. Each juror independently went through the case and took notes. Each then drew conclusions as to whether the client had changed and if so how, if therapy contributed to the change, and if so, how. The first author then independently dialogued with each of the other two jurors. The conclusions presented below are his summary. However, they have been checked by each of the other two jurors. The notes of each of the jurors are included in Appendix 2.

\section{Summaries of the Observations of the Three Jurors}

\section{$\underline{\text { Art }}$}

Art thought that Jane had shown progress in dealing with intrusive memories - they began to dominate consciousness less. There was no explicit evidence on her feelings of sadness but some suggestion that she was better at letting it go. There was some evidence of a beginning shift in how she related to men, from overfocusing and over-taking-care of them, to more of a focus on herself. There was no evidence that her headaches had improved although there was a general statement that she felt better. In terms of her "forgive and forget" goal there had been a shift in acceptance towards her mother. There also appeared to be a shift from talking about how she was bad and wrong.

The therapist contributed to the change by offering new points of view that Jane used as a foil. She tried them on for size and experimented with them. He supported her as she tried out new behaviors in and outside of therapy. He also made new distinctions in some of her old points of view. The therapist was also a catalyst in the sense that her being in therapy seemed to lead to 
her taking helpful actions initiated by herself but not suggested by the therapist. Yet these seemed to be related to her being in therapy. She also appeared to become more productively reflective in therapy. While she had previously done a lot of thinking that was not productive, having a companion in therapy seemed to help her own thinking become more productive. Overall therapy contributed to change, but outside events and the client's own change efforts also played a significant role.

\section{$\underline{\text { Karen }}$}

Karen thought that Jane had changed at a fundamental level. Eventually the change process set in motion could lead to personality change at a core level-something basic to her approach to social relating. The client will not be able to return to a state of not-knowing. The change in how she related to her mother could eventually generalize. She also seemed less constrained by her role. She acquired views that will alter her self identity (the meaning of what she has to offer and how she can take better care of herself). She was also better able to tolerate pain and cope.

Karen thought therapy contributed to Jane's change. Jane needed people on the outside of her problems to help her unfold the problems. The therapist gave her tools. Therapy was a different context with different rules than she was used to. One of the learnings she got from therapy was that it was useful to entertain other people's feedback, consider it, and experiment with it. By sharing experience with the therapist, it wasn't just "her experience," she began to get a dual perspective on relationships, and saw that some of the ways she was treated were wrong.

Jane was given just enough to unsnag her. Therapy helped her so she can keep from being stuck in a painful cycle of intrusive memories and incomplete relationships. However, Jane was an active client. She considered Joe's (the therapist's) perspective and tested their implications. She didn't wholesale adopt what he offered but learned to make distinctions about when her old strategies fit. Therapy also helped her see the "meaning in the madness" and led to greater calm. Her somatic stomach was also gone. Karen also thought the trusting relationship that Jane developed with a man, Joe, was an important component of the change process.

\section{$\underline{\text { Gayle }}$}

Gayle thought that Jane had changed. In particular Jane's attempt at controlling relationships through trying too hard to please men had changed significantly. Secondly she changed from feeling that she was "beyond help" to feeling a sense of agency. The therapist helped by changing the language that Jane was framing her problems in, for instance, from Jane's attempt to "forgive and forget" the past to "grieve" the past. This shift allowed traumatic memories to emerge and begin to be integrated.

The change process itself was one of learning new language while practicing new behavior. Keeping a diary probably played a role. The therapy sessions were "touchstones" rather than "lifelines" that the client could use from which to launch her own efforts at change. The client was able to allow herself, in therapy, to be wrong, right, ambiguous, truthful in ways she formerly thought cruel, and to act as a peer rather than a child. She was able to try out new 
Validity of Descriptive and Causal Statements about Psychotherapy Process and Outcome

A.C. Bohart, K.L. Tallman, G. Byock, \& T. Mackrill

Pragmatic Case Studies in Psychotherapy, http://pcsp.libraries.rutgers.edu

Volume 7, Module 1, Article 8, pp. 101-144, 02-28-11 [copyright by authors]

behavior and see how it fit. She could practice an "I-focus" and learn to tolerate silence without having to fill up other people.

\section{Synthesis}

The synthesis is provided by the first author. However, it was checked with the other two jurors. First, all three jurors concluded Jane had changed. There was no evidence that the headaches had gotten better. However, on the issue of the intrusive memories Jane had shifted from trying to "forgive and forget" them to confronting them. She subsequently reported to the therapist for the first time not having intrusive thoughts disturbing her sleep. She showed a gain in "forgiving and forgetting" in that she held a conversation with her mother in which she was open with her and came away with a new perspective that her mother had had her own problems.

With men her problem was that she tried to control the interaction by taking excessive responsibility to make the man happy. She reported deliberately not doing this to see what happened, and in so doing, confronted her fear that she would be boring. She also reported telling a man she was not interested in him. She reported that her feeling there was something fundamentally wrong with her changed after the first therapy session. Evidence supported this in that she subsequently talked about problems more specifically as problems rather than making trait inferences about herself. Furthermore she actively attacked many of the problems.

In terms of how much change had occurred, all three jurors thought that change had occurred but that there was more work to do. Art and Karen thought the amount of change was "moderate" or "in process." Karen thought Jane had gained some fundamental changes in how she saw the world that would not go away. Karen thought that although these changes were fundamental, there was still more to do. She thought Jane had gained "tools" that would help her with subsequent changes. Gayle thought Jane had made a significant change on the issue of trying to be controlling in relationships. Both Karen and Gayle thought there had been some shift in identity. However, Gayle too thought that there would be a further process of change.

All three jurors thought that therapy had contributed to the change. Below is the first author's synthesis of the ways he, Gayle, and Karen thought that, based on evidence, therapy had contributed to change.

1) The therapist made direct suggestions, usually in the form of a new perspective. The client tried them on for size and actively experimented with them. Example: the therapist reframed Jane's sadness as grief and suggested she needed to mourn what she had experienced in childhood. Reframing as grief contributed to Jane's confronting memories of abuse when in turn led to a working through which led to intrusive thoughts not bothering her as much.

2) The therapist differentiated meaning or "re-languaged" her problems. He reframed her goal of forgiving and forgetting as a need to mourn. He suggested that it did not have to be either/or with Jane's mother: either Jane try to change the mother, or Jane have nothing to do with the mother. Jane could accept that the mother likely would never change, and still have a relationship with her. Jane adopted this idea. 
3) The therapist supported new behavior. When Jane spontaneously decided to tell a man she was not interested in him, something very hard for her to do, the therapist was supportive afterwards when Jane was experiencing conflict over having done this. This helped Jane give up the idea she needed to make everyone happy.

4) The therapy context was helpful as an opportunity, a context, or a catalyst, without the therapist specifically doing anything. After the first session Jane got over feeling like she was fundamentally damaged, primarily because the therapist's actions of suggesting she look for meaning in her behavior led her to infer that her behavior and feelings did make sense. Therefore she was not "crazy." Also, Jane became actively reflective on her experience outside of therapy. Although she was never instructed to do this by the therapist, engaging in reflection in therapy led her to do it outside (diary writing also undoubtedly contributed). After the first session of therapy she talked with a friend who was also an adult children of alcoholics who was also in therapy. They compared notes on being in therapy and on their past experiences and through the process Jane got a lot of validation for her experience. This also contributed to her feeling that she was not "crazy." She also talked with her brother. They compared notes on their family experience and this also led to validation for Jane. These conversations appeared to be precipitated by her being in therapy, although the therapist did not suggest that Jane engage in them.

Jane also spontaneously, without the therapist suggesting it, tried out various experiments based on her experience in therapy, such as telling the man she was not interested in him, deliberately trying to not be so controlling in a relationship with a man, and so on. These were not things the therapist had assigned her to do. They were her own ideas, yet we felt that the context of therapy had been a catalyst for them.

5) The therapeutic relationship with a man whom she could trust probably helped work through some of her feelings about men.

Did therapy "cause" change? The paths to change were complex and multidetermined. The therapist contributed, but the client was active and generative in her own right. Discussions with others outside therapy also contributed significantly. Diary writing undoubtedly contributed. In-session events did not appear to be the primary "cause" of change. Rather it was primarily the client's active seeking and experimenting, based in her experience of therapy as "touchstone." Yet therapy seemed to directly contribute and to set the stage and support these experiments.

\section{Degree Of Juror Agreement}

The adjudication method, patterned as it is after what a jury does, does not require reliability on the judgments that lead each juror to draw his or her conclusions. As with a jury, different jurors might weigh evidence somewhat differently and follow somewhat different pathways to their conclusions. Yet all may reach the same conclusion. As we have previously mentioned, this is also true of other research juries, such as the juries of reviewers for professional journals. As can be seen from our discussion, and from the notes in Appendix 2, the three jurors did focus on somewhat different aspects. Nonetheless many of the differences appeared to be a matter of language. For instance, Art talked about the therapist "differentiating meaning" while Gayle talked about the therapist "re-languaging." Karen talked about the client experiencing a change in identity while Gayle talked about the client's increased sense of "I" and 
Validity of Descriptive and Causal Statements about Psychotherapy Process and Outcome

A.C. Bohart, K.L. Tallman, G. Byock, \& T. Mackrill

Pragmatic Case Studies in Psychotherapy, http://pcsp.libraries.rutgers.edu

Volume 7, Module 1, Article 8, pp. 101-144, 02-28-11 [copyright by authors]

of agency. Art talked about the Jane using the therapist's ideas as a foil, while Karen talked about the therapist giving Jane tools.

As a kind of "reliability check," Art and Karen went through the 39 suggested criteria for judging whether change had occurred (see Appendix 1) and found that they agreed on 37 of the 39. Of the 17 suggested criteria for deciding whether therapy had contributed to the change or not (see Appendix 1), they agreed on 14.

\section{OVERALL CONCLUSIONS}

\section{Change Processes in the Case of Jane and Joe}

First, we believe that, based on a rich data record, we can plausibly draw the conclusion that Jane experienced changes over the course of the time she was in therapy, and that therapy contributed to those changes. Second, we believe that an examination of a rich case record, such as was available in this case, allows a sensitive and detailed insight into how therapy contributed to the change process. Striking to us was the finding that simply being in therapy may precipitate the client doing things on her own to foster the change process, without the therapist specifically suggesting anything. At the same time there was other evidence that the therapist's actions specifically fostered the change process in specific instances. Thus therapy may contribute to change in multiple ways.

Third, it was striking for the first author, who has been a reviewer for a number of professional journals, to discover how much this process resembled a journal review. The writeups of the three authors all came to the same or similar conclusions, but, as with journal reviews, the reasons given and the way the evidence was sorted and considered was framed somewhat differently from juror to juror, although in this case the differences were more ones of language and emphasis than of kind.

\section{The Research Jury Method}

The research jury method is a method still in formulation. There are a number of unanswered questions about it. First, just what is a "sufficiently rich case record?” In the three studies conducted so far, the case record varied in richness from questionnaires filled out by clients between and after sessions and after therapy had ended, to a lengthy and detailed case write-up based on diaries and session tapes, to a complete set of session tapes with pre- and posttherapy interviews.

Second, who should the jurors be? In our three studies they have consisted of a professor in clinical psychology and a master's level clinical psychology graduate student in the Bohart and Boyd study, six graduate and undergraduate psychology and marriage and family therapy students in the Bohart and Humphreys (2000) study, and a professor in clinical psychology, a $\mathrm{PhD}$ in educational psychology who currently works as a medical researcher at Kaiser Permanente, and a college instructor in psychology with an M.A. in clinical psychology. Our jurors thus all had an interest in and some degree of familiarity with psychology. However they came from varying backgrounds, with various degrees of investments in clinical psychology. 
Ideally we could imagine a research jury consisting of experts in clinical psychology, as well as novices who would be capable of bringing fresh views, as well as possibly some with no background in psychology.

Third, in our investigations we have utilized qualitative data. This was on purpose as an attempt to see if a "human science" method could be developed to assess psychotherapy outcome. However, could quantitative data be included? In real juries some of the evidence is in quantitative form (for instance, DNA evidence). The method does not require the exclusive use of qualitative data. There is no reason that quantitative data could not be included, as Elliott (2002, 2009) does in his Hermeneutic Single Case Efficacy Design.

Fourth, what are the implications of this method for the issue of evidence-based practice? Could this method be utilized to produce evidence that a particular approach to therapy "works"? We believe it could. Suppose we were to replicate the method with a number of clients in, say, existential psychotherapy. This method would give us somewhat different data compared to a quantitative RCT design. Instead of ending up with an average change score for a group of clients that received therapy compared to an average change score for a placebo group, we would have an absolute frequency of how many clients were helped, a differentiated map of how they were helped, and whether it appeared that existential therapy had contributed to the change process. Over time we might be able to tell potential clients that existential therapy has a certain probability of producing this kind of outcome and a different probability of producing that kind of outcome. In addition, from an evidence-based perspective, we would be able to develop more differentiated maps about how therapy helped. This method would therefore allow differentiated comparisons to other therapies and in the long run, allow consumers to make more informed choices.

\section{REFERENCES}

Anderson, C. A., Berkowitz, L., Donnerstein, E., Huesmann, L. R., Johnson, J. D., Linz, D., Malamuth, N. M., \& Wartella, E. (2003). The influence of media violence on youth. Psychological Science In The Public Interest: A supplement to Psychological Science, 4(3), 1-110.

Bohart, A., \& Boyd, G. (1997a, December). A Qualitative Analysis and Study of Outcome in Psychotherapy. Paper presented as part of a poster on "Clients' construction of the therapy process: A qualitative analysis” (poster was split into two papers). Meeting of the North American Society for Psychotherapy Research, Tucson, AZ.

Bohart, A., \& Boyd, G. (1997b, December). Clients' construction of the therapy process: A qualitative analysis. Paper presented as part of a poster on "Clients' construction of the therapy process: A qualitative analysis” (poster was split into two papers). Meeting of the North American Society For Psychotherapy Research, Tucson, AZ.

Bohart, A. C., \& Humphreys, C. (2000, June). A qualitative "adjudicational" model for assessing psychotherapy outcome. Paper presented at the meeting of the International Society for Psychotherapy Research, Chicago, Illinois. 
The "Research Jury" Method: The Application of the Jury Trial Model to Evaluating the

Validity of Descriptive and Causal Statements about Psychotherapy Process and Outcome

A.C. Bohart, K.L. Tallman, G. Byock, \& T. Mackrill

Pragmatic Case Studies in Psychotherapy, http://pcsp.libraries.rutgers.edu

Volume 7, Module 1, Article 8, pp. 101-144, 02-28-11 [copyright by authors]

Bohart, A., O’Hara, M., \& Leitner, L. (1998). Empirically violated treatments:

Disenfranchisement of humanistic and other psychotherapies. Psychotherapy Research, 8, 141-157.

Burns, R. P. (2001). A theory of the trial. Princeton, NJ: Princeton University Press.

Campbell, D. T., \& Stanley, J. C. (1967). Experimental and quasi-experimental designs for research. New York: Rand McNally.

Division 32 Task Force (2004). Recommended principles and practices for the provision of humanistic psychosocial services: Alternative to mandated practice and treatment guidelines. Humanistic Psychologist, 32, 3-75.

Dreier, O. (2008). Psychotherapy in everyday life. New York: Cambridge University Press.

Elliott, R. (2002). Hermeneutic single-case efficacy design. Psychotherapy Research, 12, 1-21.

Elliott, R., Partyka, R, Alperin, R., Dobrenski, R., Wagner, J., Messer, S.B., 4, Watson, J.C., \& Castonguay, L.G. (2009). An Adjudicated hermeneutic single-case efficacy design study of experiential therapy for panic/phobia. Psychotherapy Research, 19, 543-557.

Freedman, J. (2002). Media violence and its effect on aggression: Assessing the scientific evidence. Toronto, Canada: University of Toronto Press.

Humphreys, C., Bohart, A., \& Dutile, R. (2000, August). Adjudication model for psychotherapy research: Psychotherapy outcome. Paper presented at the American Psychological Association Convention, Washington, DC.

Krause, M. S., \& Lutz, W. (2009). Process transforms inputs to determine outcomes: Therapists are responsible for managing process. Clinical Psychology: Science and Practice, 16(1), 73-81.

Mackrill, T. (2008). The therapy journal project: A cross-contextual qualitative diary study of psychotherapy with adult children of alcoholics. Unpublished Doctoral Dissertation. Copenhagen University, Denmark.

Mackrill, T. (2011a). A diary-based, cross-contextual case study methodology: Background for the case of “Jane and Joe.” Pragmatic Case Studies in Psychotherapy, 7(1), Article 10, 156-186. Available: http://hdl.rutgers.edu/1782.1/pcsp_journal

Mackrill, T. (2011b). The case of "Jane and Joe": A diary-based, cross-contextual case study. Pragmatic Case Studies in Psychotherapy, 7(1), Article 11, 187-229. Available: http://hdl.rutgers.edu/1782.1/pcsp_journal

Miller, R.B. (1999, August). Doing justice to the case study method. In R. Miller (Chair), Case study standards and the knowledge base of professional psychology. Symposium conducted at the $107^{\text {th }}$ Annual Convention of the American psychological Association, Boston.

Norcross, J. C., Beutler, L. E., \& Levant, R. (Eds.), Evidence-based practices in mental health. Washington, DC: American Psychological Association.

Petrinovich, L. (1979). Probabilistic functionalism: A conception of research method. AmericanPsychologist, 34, 373-390.

Read, J., Mosher, L. R., \& Bentall, R. P. (Eds.). (2004). Models of madness: Psychological, social and biological approaches to schizophrenia. London, England: Routledge.

Seligman, Martin E. P. (1995). The effectiveness of psychotherapy: The Consumer Reports study. American Psychologist, 50, 965-974.

Stiles, W. B. (2009). Responsiveness as an obstacle for psychotherapy outcome research: It's Worse than you think. Clinical Psychology: Science and Practice, 16(1). 86-91. 
Rozin, P. (2001). Social psychology and science: Some lessons from Solomon Asch. Personality and Social Psychology Review, 5, 2-14.

Shermer, M. (2006). Why Darwin matters: The case against intelligent design. New York: Times Books.

Task Force on Promotion and Dissemination of Psychological Procedures, Division of Clinical Psychology of the American Psychological Association (1995). Training and dissemination of empirically-validated psychological treatments: Report and recommendations. The Clinical Psychologist, 48, 3-23.

Westen, D., \& Weinberger, J. (2004). When clinical description becomes statistical prediction. American Psychologist, 59, 595-613. 


\section{APPENDIX 1: CRITERIA USED BY THE THREE “JURORS” TO JUDGE THE CASE OF JANE (FROM BOHART \& HUMPHREYS, 2000)}

\section{Instructions to “Jurors"}

Our goal is to see if we can decide from a detailed case history if a client has changed or not. We want to use an adjudicational model, as if you were a JUROR trying to make a decision on a case in court. We wwant you to take detailed nots on the case you listen to, and then make an overall judgment at the end if you think the evidence supports the claim that therapy helped or didn't help. We would like you to be specific about how it helped if you conclude that it did help, and specific about why it didn’t help if you conclude it did not help. We would like you to keep track of both supporting and contradictory evidence.

Then make two cases. The first is a case for or against the idea that the client has gotten better, made progress in resolving some or all of his or her problems, or has made some kind of personality change. Pretend you are in the jury room trying to decide on a verdict, and you are making the case one way or the other as you see it. What kind of argument would you muster and what kind of evidence would you use to support your conclusion? If you are uncertain, it is important that you say that and then say why you could not draw a conclusion-what evidence is missing? If yu want to conclude that the person did change for the better, some of the alternative hypotheses you would like to rule out are: the client is just saying that he or she has gotten better to please the researchers or the therapist, the client says he or she has gotten better because he or she has enjoyed the therapy experience and feels better but no real change has taken place, the client is acting better in therapy but that doesn't mean the client is acting better outside of therapy. Be sure to mention any evidence that contradicts your conclusion, although you may want to try to explain it.

The second case you want to make is for or against the idea that therapy contributed to the client's changing (if you think the client changed). Alternative hypotheses, for instance, are: the client was getting better before entering therapy, and process just continued; or factors in the client's life were responsible for the changes and therapy had nothing to do with it. Still another alternative hypothesis is that clients come to therapy when things are at their worst point, and things usually just naturally ease up a little. What kind of evidence can you adduce one way or the other?

At the end we will hold a mock "trial” and everyone will present their case and make their argument. You may even want to decide if you think the evidence is "beyond a reasonable doubt" as in criminal trials, or the less rigorous "preponderance of evidence" criterion used in civil trials. [NOTE: this was left in the instructions but we did not actually do this in the current case of Jane. It was done in the Bohart \& Humphreys (2000) study.]

For CASE ONE decide:

a. IF any changes too place, or any progress was made, and if so how much and what kind.

b. OR that no progress was made, or that things even got worse 
Validity of Descriptive and Causal Statements about Psychotherapy Process and Outcome

A.C. Bohart, K.L. Tallman, G. Byock, \& T. Mackrill

Pragmatic Case Studies in Psychotherapy, http://pcsp.libraries.rutgers.edu

Volume 7, Module 1, Article 8, pp. 101-144, 02-28-11 [copyright by authors]

c. Or that there was not enough evidence to make a decision.

For CASE TWO (WHICH ONLY HOLDS IF YOU THINK THE CLIENT CHANGED IN CASE ONE) decide:

a. IF therapy contributed to the change process, and if so how much and in what way

b. Or that change was due to a naturally occurring upward moving resolution process that would have happened anyway

c. OR that change was due to factors in the client's life: changes in job status, in relationship status, in friendships, in school, etc.

d. OR that the client had come in at the peak point of feeling troubled, and had naturally moved back to a less extreme position.

\section{Criteria for "Jurors"}

These criteria are not definitive. They are just suggestions. Please keep track of any criteria you use to make decisions and we can add or modify this list.

\section{Evidence That the Person Changed}

- Clients note themselves that they have changed.

- They mention things that make it clear that clients either did something or experienced something different than what they normally do or experience in the course of their everyday lives.

- Clients are relatively specific about how they have changed.

- $\quad$ They provide supporting detail.

- They show changes in behavior in the therapy session plausibly related to the kinds of changes they should be making outside of the session.

- Plausible reports by the clients that others have noted that the client has changed.

- Plausible indicators reported by the client: better grades, promotion at work, less use of medication, new activities such as jogging.

- They mentioned problems that didn’t change.

- They mention degrees of change.

- The changes mentioned seem plausible given the degree of difficulty of the problem, degree of time in therapy.

- If there is a major change reported, it is described in rich enough detail to be plausible

\section{Specific Changes}

- If the client comes in depressed they show a reasonably consistent change in mood; more ups than downs as therapy goes on--i.e. come to therapy less often depressed, seem less depressed, recover more quickly. 
Validity of Descriptive and Causal Statements about Psychotherapy Process and Outcome

A.C. Bohart, K.L. Tallman, G. Byock, \& T. Mackrill

Pragmatic Case Studies in Psychotherapy, http://pcsp.libraries.rutgers.edu

Volume 7, Module 1, Article 8, pp. 101-144, 02-28-11 [copyright by authors]

- If they report being anxious, they report either managing it better, or reductions in anxiety in key situations, and this shows a positive trend over therapy.

- If they report being unable to leave their house (agoraphobia) they report an example suggesting that they made a new and more concerted effort to go out and it met with at least some degree of success, and their affect about trying it is positive and hopeful (i.e. there is an increase in perceived possibility for them that they can do it).

- If their problem is a habit problem (studying, overeating, drinking, smoking, etc.) they report concrete changes. With a habit problem ONE incident of change is not usually enough to say that a substantial change has occurred. We would want evidence that this one change was something new, or a new attempt after having been discouraged. But we would like it better if the person could report several successes; a pattern of success. But if a few fresh changes were made and the person seemed optimistic, that we could take as preliminary evidence of change.

- If the problem is a demoralization problem ("I can't”), or involves demoralization, the person begins to show hope and optimism--a sense of possibility. MORE IMPORTANT, a sense that it will be a challenge. They become challenge oriented. THIS IS MOST IMPORTANT. If they fail they focus more on learning from the challenge than on what it means about them in terms of their inadequacy. In fact, they focus more on the difficulty of the task than on their inadequacies. In other words, when they fail they no longer see it as a complete sign of their inadequacy, or their failure. If they choose not to pursue it any further it is after a reasonable evaluation where they conclude reasonably that a shift in priorities is in order, or action plan.

- Evidence of new-found confidence in judgment.

- Evidence of greater competence in judgment--as the individual thinks out the problem he or she does it more proactively, considers alternatives, weighs them, uses good intuition. Does not seem driven by fear and jump to conclusions. They weight options aloud, think things out.

- Evidence of greater proactive determination and persistence in relation to a reasonable goal.

- If they make a risky choice, they seem to make it in a reasonable way.

- Arriving at a major decision that the person was struggling with coming up with a whole new plan which is innovative.

- Getting a new perspective which brings greater coherence, reduces debilitating guilt, gives new positive behavioral options, helps the person let go of something from the past

- Gaining a new perspective where they seem to be acceptantly criticizing themselves, seeing their own limitations, but not in a defensive or overly critical way. A balanced way. Increased productive meta-cognitive functioning.

- Gaining a perspective that "I am not my problem.” 
- Identity work: clarifies fundamental goals and values. If no goals or values, begins to confront these issues. If has adopted goals and values from parents but is beginning to question them, begins to evaluate for self. If is in an "identity crisis," or moratorium, struggles with issues and makes progress in making commitments. Identity work can take place in any or all of the following areas: vocational goals, moral values, goals about relationships, goals about children, religious values, political values, values about what makes for a meaningful life, gender issues, sexuality, ethnicity and cultural background.

- Identity work: Real self controversies--what is my real self, am I being untrue to my real self? Movement towards some kind of reconciliation or decision.

- Traumatic experiences--signs of letting go of it, coming to terms with it, reductions in symptoms such as flashbacks or nightmares, or at least a greater sense that these can be handled and not so debilitating.

- Achievement of specific goals--becoming more assertive, as evidence by self-report of concrete instances, perhaps seeming more assertive in the therapy session, rise in confidence.

- Interpersonal changes--reported changes in a positive fashion in relationships--handling anger better, less dependence, greater problem solving, greater realistic acceptance of others (i.e., but NOT accepting certain things such as abuse), greater empathy as demonstrated towards others and towards the therapist (more careful listening, less confrontive). With therapist acts more proactively, dialogically, less dependent, less aggressive, less need for dominance.

- Specific changes: finished a project, made attempts to protect daughter, exercising. Made a new friend. Got and kept a job.

- Greater realization that there may be some things that will take ongoing work.

- Changes in self-relationship. Greater realization and appreciation of accomplishments; more specific and concrete and accurate assessment of talents and effort; less global, negative self-attributions; greater self-empathy; greater self-listening to intutions, felt experiencing; greater receptive internal dialogue; holding constructs more tentatively to evaluate them; more of an open, searching mentality; if overinflated self-esteem or selfconfidence, taking a more careful look at how one might be doing, offending people, etc.

- Reduction in any presenting symptoms, such as feeling weak, fearful, tiring quickly, feeling no interest in things, feeling stressed, blaming oneself, feeling suicidal, unfulfilling sex life, feeling lonely, frequent arguments, difficulty concentrating, feeling hopeless about the future, having disturbing thoughts come to mind, upset stomach, sweating, dizziness, heart pounding, trouble getting along with others, trouble sleeping, headaches.

- Increases in positive things: self-efficacy, enjoying spare time, feeling loved and wanted, greater happiness, greater sense of direction or optimism, greater acceptance of the injustices of life in a productive way.

- Better ability to define goals in a proactive and functional way. 
Validity of Descriptive and Causal Statements about Psychotherapy Process and Outcome

A.C. Bohart, K.L. Tallman, G. Byock, \& T. Mackrill

Pragmatic Case Studies in Psychotherapy, http://pcsp.libraries.rutgers.edu

Volume 7, Module 1, Article 8, pp. 101-144, 02-28-11 [copyright by authors]

- Prosocial changes--volunteering, involvement in productive activities, new projects.

- Changes in physiology--less sweating, more calm and relaxed in therapy.

- Changes in appearance in a positive fashion (if observed).

\section{Evidence That It Was Therapy That Helped}

- Clients themselves report that therapy helped.

- Clients are relatively specific about how therapy helped, and it is described in a plausible way.

- Outcomes are relatively specific and idiosyncratic to each client and vary from client to client (if comparing across clients).

- In their reports, clients are discriminating about how much therapy helped, i.e. they do not in general give unabashedly positive testimonials.

- They describe plausible links to the therapy experience.

- They mention things that didn't help.

To the rater a plausible narrative case can be made linking therapy work to positive changes. This includes:

- Therapy provides a work space where clients have an opportunity to talk, think, express. The things the client talks about are the things that change, or if other things change, the client notes a relationship of them to the therapy experience. Client notes that this helped.

- Therapist's empathic understanding, warmth, acceptance, seems to relate to client's increased engagement, willingness to try new things, productive exploration.

- Therapist's encouragement, support, positive attitude seem to be related to client's overcoming demoralization, willingness to confront challenges, not be discouraged by failure. Therapist supports client productively when client fails. Keeps eye focused on productive behavior and this seems to relate to client's doing so also.

- Therapist's warmth, empathic listening, seems to provide safe atmosphere for client to confront painful experiences, and these in turn change.

- Therapist's in-tune questions, reflections, interpretations, or comments, seem to facilitate clients' exploration, gaining new perspectives, developing action plans, creativity. Client feels recognized.

- Clients engage in concrete procedures in therapy and changes are congruent with what they are trying to achieve, and there is evidence of these changes. Examples: EMDR-clients work through a traumatic experience and then seem relieved afterwards, and at the next session; clients engage in chair work and either resolve an internal conflict, or come 
to terms with someone they have unresolved feelings towards; and this change persists or at least partially persists in subsequent sessions; clients challenge dysfunctional cognitions and show plausible changes in mood or behavior.

- Mahrer's good moments and plausible relationships to change.

- Issues client struggles with in therapy change plausibly over time in acccord with the trajectory of the client's working on them. E.g. client talks about them week after week, and has ups and downs, but gradually masters them, and the mastery seems related to their ongoing struggle with it in therapy. In other words, perhaps each week they talk about experiences related to resolving the problem, works on it, and gradually masters it.

- Clients report changes in trajectory from their past life in the problem. Clients report something new in regard to coping with the problem, and relate it to therapy, or it seems related to therapy. Clients report a history of failed coping with the problem, and now it is changing. Even if client reports having tried some of these things before, now reports that therapy has helped have confidence in the effort and helps him or her persist.

- There are no plausible life changes that could have assumed major responsibility for the change. Or, if there is a life change, it seems to be a result of therapist deliberative activity, or it gets incorporated into the therapy activity in a productive way.

- Topics not dealt with in therapy did not change, or, if they did change, there was a plausible reason why they changed from the therapy or from clearly independent reasons. In other words, they can be accounted for so that we can assume we are not talking about a global halo effect.

- Clients' mastery experiences, problem actuation, and clarification and gaining of new perspectives that occurs in therapy are related to the changes.

\section{For CASE ONE decide:}

a. IF any changes took, or any progress was made, and if so how much and what kind.

b. OR that no progress was made, or that things even got worse.

c. OR that there was not enough evidence to make a decision.

\section{For CASE TWO (WHICH ONLY HOLDS IF YOU THINK THE CLIENT CHANGED IN CASE ONE) decide:}

a. IF therapy contributed to the change process, and if so how much and in what way.

b. OR that change was due to a naturally occurring upward moving resolution process that would have happened anyway.

c. OR that change was due to factors in the client's life: changes in job status, in relationship status, in friendships, at school, etc.

d. OR that the client had come in at the peak point of feeling troubled, and had naturally had moved back to a less extreme position.. 


\section{Evidence That The Person DID NOT change}

- Clients note themselves that they did not change.

- They mention things that make it clear that clients are still acting as they had in the past, or have gotten worse.

- Clients are relatively specific how their life is still the same.

- They provide supporting detail.

- They seem the same in the therapy session.

- Plausible reports by the clients that others have noted that the client has not changed.

- Plausible indicators reported by the client: no change in grades, promotion at work, use of medication, new activities such as jogging.

- No evidence of greater confidence, better balance in judgment, more proactive stance towards problems, better ability to cope with challenge. They still seem impulsive in decision-making, or overly conservative, or fear-driven.

- No evidence of greater persistence in pursuing reasonable goals.

- No new meaningful shifts in perspective.

- No greater clarity in identity work--goals, values, etc.

- No cessation or reduction in symptoms.

\section{No Evidence That It Was Therapy That Helped}

- Clients ascribe changes to events in their life

- In their reports, clients are not discriminating about how much therapy helped, i.e. they give unabashedly positive testimonials, but provide few details about how it helped.

- They mention things that didn't help.

- Changes described in client's life could plausibly account for client's changes whether client sees it that way or not.

No Evidence Of A Plausible Narrative Case Linking Therapy Work To Positive Changes. This would be the OPPOSITE of what is given above. 
Validity of Descriptive and Causal Statements about Psychotherapy Process and Outcome

A.C. Bohart, K.L. Tallman, G. Byock, \& T. Mackrill

Pragmatic Case Studies in Psychotherapy, http://pcsp.libraries.rutgers.edu

Volume 7, Module 1, Article 8, pp. 101-144, 02-28-11 [copyright by authors]

- Therapy provides a work space where clients have an opportunity to talk, think, express, but changes seem unrelated to client problem-solving activity.

- Therapist's empathic understanding, warmth, acceptance, do not lead to client's increased engagement, willingness to try new things, or productive exploration.

- Therapist's encouragement, support, positive attitude seem unrelated to client's overcoming demoralization, willingness to confront challenges, not be discouraged by failure.

- Client never appears to view therapy atmosphere as a safe place.

- Client is resistant, defensive, or uncooperative throughout.

- Clients engage in concrete procedures in therapy but no changes occur.

- There are no "good moments." 


\section{APPENDIX 2: WORKNOTES FROM EACH OF THE THREE “JURORS” IN THE CASE OF JANE AND JOE}

\section{Overall Conclusion}

\section{Art's Notes}

Problems and outcomes:

Intrusive memories: progress--increase (sluice opens), but helps to live with them, they begin to dominate consciousness less.

Sadness: no clearcut evidence, but implication that she is better able to handle the sadness. Reframing it as appropriate. Some evidence of letting go.

Men: No evidence of establishment of a new good relationship (no surprise in 12 sessions). However some evidence of a beginning shift in how she will be in relationships from overfocusing on him and overtaking care of, to more of a focus on her, experimenting with letting him take care of her. Telling one man she didn't think they fit (very hard for her and it is still ego dystonic).

Headaches: No evidence although she does make a general statement that she feels better.

Forgive and forget: Shift in acceptance towards mother.

"I am wrong” (this is more of a construct of Mackrill's); beginning shift in how she reframes this problem. Linguistic evidence of a shift. Talks not so much as she is bad and wrong, more about the problem as an "it." Also says she no longer worries that she has "gone to the rats.” AND is very actively pursuing changing her problems by experimenting in world (contra a I am fundamentally damaged bad and wrong model, which usually leads to a waiting on the therapist to fix one).

Overall: says she feels better.

Overall conclusion: some evidence of progress in the form of beginning change. Some evidence of shifts towards new ideas, new ways of framing things. Evidence of experimenting with new ways of being. No evidence of completed major life stance shifts. No evidence of resolution of problems. Overall I'd say “some” change. On a 0-10 scale, I'd say about 5.

$\underline{\text { How Much Did Therapy Contribute? }}$

He offers new points of view that she uses as a foil. She doesn't always directly accept (challenging medical model). Rather she tries on for size and experiments with. (as a direct coach)

He supports her in trying out new behaviors in and outside of therapy. In therapy: opening up and self-disclosing and exploring. Outside: taking risks, such as telling the man the truth. Also: reconciling with mother. (as a source of validation and support, as a "reality check" )

In offering new points of view he "differentiates meaning," i.e., makes new distinctions, such as that it is not either/or with mom: either you try to change her or you don't relate to her. You can realize she'll never change and still have a relationship with her. 
As a catalyst. She goes out and talks to friend, implicitly about the therapy experience, and she and friend come up with new normalizing insights and ideas. She learns through friend. Yet indirectly her going to therapy has stimulated her to do this. (As a literal catalyst, and as a foil)

As an opportunity: I need notes on this. He provides a supportive workspace. How does she use being in therapy as an opportunity? I think in her being a highly active agent who goes beyond what therapist offers to generate her own experiments, own ideas. She is continually exploring. She becomes more reflective, precipitated as a part of therapy (an indirect consequence, although modeled by therapist and implied by therapist, but you have sense she has already been reflective. It is more that she gets unstuck from some ideas and her reflection moves forward. I had the STRONGEST sense that it was important to have a companion. SHe is described as doing a LOT of thinking herself that is not productive, until she does it in therapy. Therapist as an implied reality checker. A presence. Rehearsing TO another person (Staudinger). Therapist doesn't tell her to say no to male friend, but she does it herself.

As another voice: he says things she's heard before from friends and others. It is the hearing it again which helps her decide to listen to it. Sense is, though, that it is the hearing it again that is important, not just that it is from this "expert” therapist.

How much does therapy help? I'd judge "somewhat.” On a 10 point scale I'd say a 7. It is clear that outside events also contribute. Not least of which is client herself. She is highly active agent-generating her own experiments and innovations; discussing with friend, reconciling with mother, which feed back and reinforce what therapist is touting. But she gets ideas from friends too. Events play a role: reconciling with mother, talking with brother. Natural maturation? I think we can rule that out because she's been in therapy before and is coming because of headaches. Implied that she's had these problems a while. Diaries also.

Conclusion: Therapist enters a complex life. His presence makes a difference, but not in ways modeled by our theories (therapist changes structures in person's head).

\section{SPECIFIC NOTES}

Page 4. Joe offers an alternative point of view on her sadness. She wants to forgive and forget (rid herself of certain experiences). Joe wants access--need to understand. Different points of view presented. Jane experienced Joe's point of view as significant, that she experienced him as approving when she cried. Joe: "You can live your way through grief." [this is close to "accept", which is a slightly different take on Jane's "forgive and forget.”]

5. Jane begins to consider Joe's pov (point of view) on grief. Her pov shifts (seems clearly influenced by Joe here). Shares traumatic experiences with Joe rather than push away. Practices the pov. Intrusive memories initially increase, then later subside. Helps her with difficulty falling asleep.

6. Her headaches. Seen a neurologist, now a cranial therapist. Neurologist said she needed to go to therapy or get antidepressants. Didn’t want antidepressants.

It is here that Mackrill says she sees herself as problematic: gone to the rats, etc. "Something 
must be wrong with my head.” This is his inference.

After the first session she writes that she is no longer afraid of being "beyond help." But it is not clear this is the therapy per se. Although seems like a fair inference because she felt she was in bad shape when neurologist referred her to therapy. How does Joe "undermine” this/ According to Mackrill by simply emphasizing connections between Jane's emotions and her life conditions. I.e. Not explicitly, but through his actions. But this is Mackrill's analysis.

8. "Jane is engaged in her own analysis." Mackrill says this is the key to her therapy. Consistently uses diary to analyze her life. She doesn’t follow the directions.

She has a journal note where she notes that nothing much has happened in her physical life, but that she feels more emotionally stable since entering therapy (fifth session).

After this entry she investigatees what has changed. Here she goes into the idea that she is not "to the rats" and because of idea of investigating connections. So here she is actively working with what Joe is implicitly and explicitly suggesting. Says there has basically been a shift from being wrong (not her language) to investigating connections

I have a note on this page: "Jane doing it herself but in the context of therapy and research. But it is important she is in therapy.”

10. The importance of therapy not being a personal relationship. she feels free to cry without worrying. She says she views it as an enormous challenge to lay her inner most thoughts bare to a man, and one who is a complete stranger. She is "daring to be open” (fourth session). Mackrill's discussion here is that a) she has had bad relationships with men in the past, but b) she is daring to be open by defining this relationship as not personal. But it does give her a chance to practice trust. He points out it is not Joe who expresses this point of view. It is the therapy context itself that implies that talking about your concerns to a complete stranger can help (and embedded in this in this case), talking to a man.

She becomes aware that she has a tendency to keep things to herself. That she is a private person. [HER OWN LEARNINGS IN CONTEXT]

11. But this is not only therapy: it triangulates with things friends have said about her. She begins to evaluate her own perspective: "apparently I like this best.”

She then proceeds to be open with a man she is dating and tells him she is not interested in him. She finds this difficult and sees herself as cruel (session 4). This is a new behavior for her. NO evidence that therapist encouraged her to do this. So THIS WOULD BE EVIDENCE OF CASH PLUS THERAPY AS CATALYST.

She also is newly open with her brother. They discover how their alcoholic mom has affected them.

12. Some examples of bad experiences with men that led her to have trust issues.

13. Talks with a friend who is a client at TUBA. Mentions her first session with Joe to friend. 
Validity of Descriptive and Causal Statements about Psychotherapy Process and Outcome

A.C. Bohart, K.L. Tallman, G. Byock, \& T. Mackrill

Pragmatic Case Studies in Psychotherapy, http://pcsp.libraries.rutgers.edu

Volume 7, Module 1, Article 8, pp. 101-144, 02-28-11 [copyright by authors]

Led to a good chat about many problems she and friend run into. Talked for three hours. Talked about possibility they have problems maintaining boundaries. For her, always trying to "sense where he is." Make sure he is happy. This is one of her "apparently" ideas--which she will try out as she goes, like Mackrill says, like a new pair of glasses.

She is dealing with that she has a problem in knowing about "where I stand and how I feel about being right there" in relationships with men. [THIS SEEMS TO BE DISCOVERED MORE THROUGH DISCUSSIONS WITH FRIEND THAN IN THERAPY, ALTHOUGH THERAPY HAS IMPLIED THIS REFLECTIVE FOCUS] this is right after first session.

Therapy emphasizes a reflective focus. As Mackrill says, "It is difficult to talk about yourself and your life to another person for an hour without becoming more aware of how your life is and what it feels like being you....” The therapeutic context reflects a point of view, according to him.

But Joe emphasizes I focus also. But Mackrill's evidence for this is Joe's journal. No clear evidence so far that he does this in therapy. Except once he talks about how he and she can talk about how they get along together. This moves Jane (second session). In her journal she notes that "apparently" she doesn't expect there to be room for her needs. SO SHE CONTINUES THEME INTO HER REFLECTIONS ON SECOND SESSION AND JOE’S COMMENT

By session 3 she is thinking that she is going to try being different with the man she has met. Not go so fast. So she is focusing on herself.

17. Joe supports Jane in doing something she feels is cruel--talking to her date and in maintaining her point of view that she is not interested in him.

Joe says being in touch with feelings a gift. Jane doesn't agree. Decide she will have to consider it. Keeps hold of Joe's pov as a foil for her's.

She remembers that a girl friend had said the same thing to her: that she wasn't responsible for another person's feelings. Mackrill makes point that idea is not new: what is new is that she is in therapy.

In session two, when Joe brings up issue of she might feel uncomfortable he is a man, she is moved. She says “apparently, I don't expect there to be room for my needs...” She discovers she has difficulty RECEIVING other's caring and attention. (sounds like to me using therapy as an opportunity).

She says in journal she is used to being the one who gives, and if turned upside down, not sure what to make of it. So then she tries a mental experiment of being in a relationship where she is not the one who gives. Concludes she might be passive and boring. then thinks maybe it is a matter of achieving balance.

Investigates it in relationship to past contexts, and to future context. Gets an insight that receiving care is itself a form of giving. this happens in journal and in session. Sessions two and three.

Then goes on date and experiments: conscious of standing back and giving him space to take the 
lead. It worked out.

21. Forgiving and forgetting doesn’t work for her. Past continues to intrude into consciousness. Joe stresses again and again understanding past to understand present. Talks about how she subordinated her feelings to her mom. Thinks she transfers this onto men.

Maybe feeling that it was cruel to tell man she wasn't interested was connected to her relationship to mom, according to Joe. Joe uses this to calm her down, even though she hasn't fully accepted his pov on this.

She ends up seeing going into the past as the single most important helpful thing in therapy--there being meaning in the madness and there being a natural cause.

BUT she has looked into the past herself and it hasn't helped to get rid of intrusive memories. Joe's pov is that it is different to do it in a sharing context.

She doesn't think anything wrong with crying, just that it is out of proportion. Thinks maybe has to do with loss of influence and credibility.

23-24. 6th session: can't talk about childhood without being emotionally touched and cry. Beginning to give up pov on forgiving and forgetting. Must deal with them. Adopts idea of investigating them. gets idea of writing them down at the time. This is Jane's idea. Joe supports. OPPORTUNITY. (as revealed by session tape).

25. She talks about how she had often tried to deal with intrusive memories. hadn’t helped. Joe: "feeling the feelings" and need for expresssion.

P. 26. But brings her a sense of hopelessness about past and grief. Joe then asks where she sees herself in the future. This helps her shift perspective momentarily at least.

p. 27. He asks her to think about if mother died. She confronts fear of her family dying. Joe says something about everyone feeling frightened about death. Normalizes it for her. Here idea of "having a witness" comes up in context of sharing when talks about past.

She likes idea of someone witnessing that it was damn hard to be jane and it wasn’t fair.

Evidence that her point of view has become more real: "The fact that I find being with men generally speaking slightly difficult shall no longer be a secret.” (journal 2).

29. But she sees sharing as "unnatural.” It "feels wrong.” But she experiments, and experiences that it helps. session ten--old memories haven’t arisen since last session. feels calmer.

31. Investigating relationships: sees a tendency to remove herself from potentially dangerous situation with a man. avoids relationships where she loses control or gives into passion. Joe suggests her insecurity with men is due to fact she is at one level a teenager who never lived through the process. He suggests a dual pov- to help her cope. She will help and reassure the teenage girl. 
32 She finds a way of dealing with intrusive memories: support herself "looking after the child.”, the use of adult eyes.

33. the sluices open (session 8). flood of traumatic memories appear. Mackrill suggests it may now be because she has a way of dealing with memories. She notes you cannot slip these into casual conversation.

Also notes more calm. Not that they don’t turn up, but aren't bothering her as much. Inner film fairly calm (session 9).

36. after speaking to Joe and writing about series of traumatic events (8-10) she experiences feelings of compassion for mom. Joe validates this. recognizes that her mom loves her. Helps her begin to realize might be other love for her in world.

38. Mom has a relapse and takes some form of drug. Joe presents idea that mom cannot face up to her own behavior. Jane goes off from this to face fact mom will probably always be like this. Recognizes that needs to face this. Joe supports.

\section{Analysis Using The Criterion List}

\section{Evidence That The Person Changed}

1. Clients note themselves that they have changed. YES

2. They mention things that make it clear that clients either did something or experienced something different than what they normally do or experience in the course of their everyday lives. YES

3. Clients are relatively specific about how they have changed. YES

4. They provide supporting detail. YES

5. They show changes in behavior in the therapy session plausibly related to the kinds of changes they should be making outside of the session. NO EVIDENCE

6. Plausible reports by the clients that others have noted that the client has changed. NO EVIDENCE

7. Plausible indicators reported by the client: better grades, promotion at work, less use of medication, new activities such as jogging. NO

8. They mentioned problems that didn't change. NO

9. They mention degrees of change YES: WHEN SHE TALKS ABOUT "APPARENTLY” AS A PROVISIONAL INSIGHT.

10. The changes mentioned seem plausible given the degree of difficulty of the problem, degree of time in therapy. YES

11. If there is a major change reported, it is described in rich enough detail to be plausible. NA 
Validity of Descriptive and Causal Statements about Psychotherapy Process and Outcome

A.C. Bohart, K.L. Tallman, G. Byock, \& T. Mackrill

Pragmatic Case Studies in Psychotherapy, http://pcsp.libraries.rutgers.edu

Volume 7, Module 1, Article 8, pp. 101-144, 02-28-11 [copyright by authors]

\section{Specific Changes}

12. If the client comes in depressed they show a reasonably consistent change in mood; more ups than downs as therapy goes on--i.e. come to therapy less often depressed, seem less depressed, recover more quickly. SADNESS APPEARS TO ALLEVIATE SOMEWHAT

13. If they report being anxious, they report either managing it better, or reductions in anxiety in key situations, and this shows a positive trend over therapy. NO. MENTIONS BEING ANXIOUS WITH MEN AND THEY DISCUSS A WAY TO COPE WITH IT BUT NO EVIDENCE IT HAS AS YET CHANGED

14. If they report being unable to leave their house (agoraphobia) they report an example suggesting that they made a new and more concerted effort to go out and it met with at least some degree of success, and their affect about trying it is positive and hopeful (i.e. there is an increase in perceived possibility for them that they can do it). NA

15. If their problem is a habit problem (studying, overeating, drinking, smoking, etc.) they report concrete changes. With a habit problem ONE incident of change is not usually enough to say that a substantial change has occurred. We would want evidence that this one change was something new, or a new attempt after having been discouraged. But we would like it better if the person could report several successes; a pattern of success. But if a few fresh changes were made and the person seemed optimistic, that we could take as preliminary evidence of change. NA

16. If the problem is a demoralization problem ("I can't"), or involves demoralization, the person begins to show hope and optimism--a sense of possibility. MORE IMPORTANT, a sense that it will be a challenge. They become challenge oriented. THIS IS MOST IMPORTANT. If they fail they focus more on learning from the challenge than on what it means about them in terms of their inadequacy. In fact, they focus more on the difficulty of the task than on their inadequacies. In other words, when they fail they no longer see it as a complete sign of their inadequacy, or their failure. If they choose not to pursue it any further it is after a reasonable evaluation where they conclude reasonably that a shift in priorities is in order, or action plan. ALTHOUGH SHE REPORTS FEELING HOPELESS AND HELPLESS, SUCH AS FEELING SHE HAS "GONE TO THE RATS,” SHE COPES WELL. AS OF THE SECOND SESSION HAS OVERCOME THIS.

17. Evidence of new-found confidence in judgment. NO EVIDENCE

18. Evidence of greater competence in judgment--as the individual thinks out the problem he or she does it more proactively, considers alternatives, weighs them, uses good intuition. Does not seem driven by fear and jump to conclusions. They weight options aloud, think things out. EVIDENCE OF SHOWING MORE REFLECTIVITY.

19. Evidence of greater proactive determination and persistence in relation to a reasonable goal. NO.

20. If they make a risky choice, they seem to make it in a reasonable way. NA 
Validity of Descriptive and Causal Statements about Psychotherapy Process and Outcome

A.C. Bohart, K.L. Tallman, G. Byock, \& T. Mackrill

Pragmatic Case Studies in Psychotherapy, http://pcsp.libraries.rutgers.edu

Volume 7, Module 1, Article 8, pp. 101-144, 02-28-11 [copyright by authors]

21. Arriving at a major decision that the person was struggling with. NA

22. Coming up with a whole new plan which is innovative. NA

23. Getting a new perspective which brings greater coherence, reduces debilitating guilt, gives new positive behavioral options, helps the person let go of something from the past. YES. THIS HAPPENS SEVERAL TIMES. GETS NEW PERSPECTIVES AND TESTS THEM.

24. Gaining a new perspective where they seem to be acceptantly criticizing themselves, seeing their own limitations, but not in a defensive or overly critical way. A balanced way. Increased productive meta-cognitive functioning. I'D SAY YES HERE. SHE SEES HERSELF AS BEING TOO CONCERNED WITH OTHERS' WELFARE IN RELATIONSHIPS, BUT DOES IT IN ACCEPTING WAY

25. Gaining a perspective that “I am not my problem.” DEFINITELY YES. GETS OVER “I'M FOR THE RATS” QUICKLY.

26. Identity work: clarifies fundamental goals and values. If no goals or values, begins to confront these issues. If has adopted goals and values from parents but is beginning to question them, begins to evaluate for self. If is in an "identity crisis,” or moratorium, struggles with issues and makes progress in making commitments. Identity work can take place in any or all of the following areas: vocational goals, moral values, goals about relationships, goals about children, religious values, political values, values about what makes for a meaningful life, gender issues, sexuality, ethnicity and cultural background. YES. RE-EVALUATES KEY VALUES IN REGARD TO RELATIONSHIPS.

27. Identity work: Real self controversies--what is my real self, am I being untrue to my real self? Movement towards some kind of reconciliation or decision. NA

28. Traumatic experiences--signs of letting go of it, coming to terms with it, reductions in symptoms such as flashbacks or nightmares, or at least a greater sense that these can be handled and not so debilitating. YES.

29. Achievement of specific goals--becoming more assertive, as evidence by self-report of concrete instances, perhaps seeming more assertive in the therapy session, rise in confidence. YES.

30. Interpersonal changes--reported changes in a positive fashion in relationships--handling anger better, less dependence, greater problem solving, greater realistic acceptance of others (i.e., but NOT accepting certain things such as abuse), greater empathy as demonstrated towards others and towards the therapist (more careful listening, less confrontive). With therapist acts more proactively, dialogically, less dependent, less aggressive, less need for dominance. YES, WITH BROTHER AND MOTHER

31. Specific changes: finished a project, made attempts to protect daughter, exercising. Made a new friend. Got and kept a job. NA

32. Greater realization that there may be some things that will take ongoing work. NO EVIDENCE

33. Changes in self-relationship. Greater realization and appreciation of accomplishments; more 
Validity of Descriptive and Causal Statements about Psychotherapy Process and Outcome

A.C. Bohart, K.L. Tallman, G. Byock, \& T. Mackrill

Pragmatic Case Studies in Psychotherapy, http://pcsp.libraries.rutgers.edu

Volume 7, Module 1, Article 8, pp. 101-144, 02-28-11 [copyright by authors]

specific and concrete and accurate assessment of talents and effort; less global, negative self-attributions; greater self-empathy; greater self-listening to intuitions, felt

experiencing; greater receptive internal dialogue; holding constructs more tentatively to evaluate them; more of an open, searching mentality; if overinflated self-esteem or selfconfidence, taking a more careful look at how one might be doing, offending people, etc. LESS GLOBAL AND NEGATIVE SELF-ATTRIBUTIONS. AN OPEN SEARCHING MENTALITY, ALTHOUGH UNCLEAR DUE TO THERAPY. SELF-ACCEPTANCE: ACCEPTANCE OF THE FACT SHE HAD IT DAMN HARD AND IT WASN'T FAIR.

34. Reduction in any presenting symptoms, such as feeling weak, fearful, tiring quickly, feeling no interest in things, feeling stressed, blaming oneself, feeling suicidal, unfulfilling sex life, feeling lonely, frequent arguments, difficulty concentrating, feeling hopeless about the future, having disturbing thoughts come to mind, upset stomach, sweating, dizziness, heart pounding, trouble getting along with others, trouble sleeping, headaches. REDUCTION IN DISTURBING NATURE OF PAST MEMORIES. NO EVIDENCE ON HEADACHES

35. Increases in positive things: self-efficacy, enjoying spare time, feeling loved and wanted, greater happiness, greater sense of direction or optimism, greater acceptance of the injustices of life in a productive way. SAYS SHE FEELS BETTER.

36. Better ability to define goals in a proactive and functional way. NA

37. Prosocial changes--volunteering, involvement in productive activities, new projects. NO

38. Changes in physiology--less sweating, more calm and relaxed in therapy. NO EVIDENCE

39. Changes in appearance in a positive fashion (if observed) NO EVIDENCE

Evidence That It Was Therapy That Helped

40. Clients themselves report that therapy helped. NOT SPECIFICALLY, ALTHOUGH SHE DOES ALLUDE TO THINGS JOE SAYS.

41. Clients are relatively specific about how therapy helped, and it is described in a plausible way. IN A SENSE. SHE DOES ALLUDE TO THINGS JOE SAYS AND HOW SHE HAS THOUGHT ABOUT THEM.

42. Outcomes are relatively specific and idiosyncratic to each client and vary from client to client (if comparing across clients). YES IN THE SENSE THAT HER OUTCOMES ARE SPECIFIC AND IDIOSYNCRATIC TO HER.

43. In their reports, clients are discriminating about how much therapy helped, i.e. they do not in general give unabashedly positive testimonials. NO EVIDENCE OF POSITIVE OR NEGATIVE TESTIMONIALS.

44. They describe plausible links to the therapy experience. IN A MANNER OF SPEAKING-SHE DOES LINK THINGS TO THINGS JOE SAYS.

45. To the rater a plausible narrative case can be made linking therapy work to positive changes. 
Validity of Descriptive and Causal Statements about Psychotherapy Process and Outcome

A.C. Bohart, K.L. Tallman, G. Byock, \& T. Mackrill

Pragmatic Case Studies in Psychotherapy, http://pcsp.libraries.rutgers.edu

Volume 7, Module 1, Article 8, pp. 101-144, 02-28-11 [copyright by authors]

This includes the following (\#47-57): YES.

46. Therapy provides a work space where clients have an opportunity to talk, think, express. The things the client talks about are the things that change, or if other things change, the client notes a relationship of them to the therapy experience. Client notes that this helped. YES. CLEAR EVIDENCE OF THIS.

47. Therapist's empathic understanding, warmth, acceptance, seems to relate to client's increased engagement, willingness to try new things, productive exploration. YES, BUT MORE FOR WARMTH AND ACCEPTANCE THAN EMPATHY. DEFINITELY SEEMS RELATED TO HER TRYING NEW THINGS.

48. Therapist's encouragement, support, positive attitude seem to be related to client's overcoming demoralization, willingness to confront challenges, not be discouraged by failure. Therapist supports client productively when client fails. Keeps eye focused on productive behavior and this seems to relate to client's doing so also. YES.

49. Therapist's warmth, empathic listening, seems to provide safe atmosphere for client to confront painful experiences, and these in turn change. YES

50. Therapist's in-tune questions, reflections, interpretations, or comments, seem to facilitate clients' exploration, gaining new perspectives, developing action plans, creativity. Client feels recognized. YES. THE WITNESS IDEA PLUS MANY POINTS OF VIEW OF THERAPIST SHE EMPLOYS.

51. Clients engage in concrete procedures in therapy and changes are congruent with what they are trying to achieve, and there is evidence of these changes. Examples: EMDR--clients work through a traumatic experience and then seem relieved afterwards, and at the next session; clients engage in chair work and either resolve an internal conflict, or come to terms with someone they have unresolved feelings towards; and this change persists or at least partially persists in subsequent sessions; clients challenge dysfunctional cognitions and show plausible changes in mood or behavior, NO

52. Issues client struggles with in therapy change plausibly over time in accord with the trajectory of the client's working on them. E.g. client talks about them week after week, and has ups and downs, but gradually masters them, and the mastery seems related to their ongoing struggle with it in therapy. In other words, perhaps each week they talk about experiences related to resolving the problem, works on it, and gradually masters it. TO SOME DEGREE THERE IS EVIDENCE FOR THIS.

53. Clients report changes in trajectory from their past life in the problem. Clients report something new in regard to coping with the problem, and relate it to therapy, or it seems related to therapy. Clients report a history of failed coping with the problem, and now it is changing. Even if client reports having tried some of these things before, now reports that therapy has helped have confidence in the effort and helps him or her persist. YES. PARTICULARLY WITH INTRUSIVE THOUGHTS.

54. There are no plausible life changes that could have assumed major responsibility for the change. Or, if there is a life change, it seems to be a result of therapist deliberative activity, or it gets incorporated into the therapy activity in a productive way THERE IS 


\section{SOME EVIDENCE LIFE EVENTS PLAYED A ROLE: TALKING TO FRIEND AND BROTHER, MOTHER HAVING RELAPSE.}

55. Topics not dealt with in therapy did not change, or, if they did change, there was a plausible reason why they changed from the therapy or from clearly independent reasons. In other words, they can be accounted for so that we can assume we are not talking about a global halo effect NO EVIDENCE

56. Clients' mastery experiences, problem actuation, and clarification and gaining of new perspectives that occurs in therapy are related to the changes. YES.

\section{NOTES AND CONCLUSIONS}

Mackrill constructed the case by carefully tracing different themes and looking at the evidence. His goal was to explore the relationships across contexts, not to make an argument for or against change. His theory was that change happens not only in therapy, which works against our hypothesis. He showed his writeup to both client and therapist afterwards and modified it slightly to fit feedback from client. So client validates what he says.

Conclusions: Therapy does NOT work by changing things inside clients. It is not an operation. It is not therapist--->client. Rather, it is therapist suggests ideas or behaves in such and such a way. Client picks this up, apprehends it, thinks about it, compares and contrasts to other experiences in her past and present life. She may try experiments on it spontaneously without therapist imput. She may come up with new insights based on it without therapist imput. Or she may try therapist ideas on for size and test them out. She then goes back and reports to therapist, who supports new ideas and experiments.

Therapist direct effects:

Therapist does suggest alternative points of view, which client juxtaposes to her's and thinks about.

Therapist supports.

Therapist indirect effects: workspace (opportunity), catalyst.

\section{Karen's Notes}

\section{INNOCENCE}

She changed in a fundamental way - with her new strategies and perspective, she probably cannot return to not knowing. The therapy could lead to personality change at a core levelsomething basic to her approach to relationships.

\section{CHANGE}

The changes she made may generalize beyond her relationship with her mother.

She is now less constrained by her perceived role. 


\section{IDENTITY/MEANING}

She has acquired views that will alter her life, including aspects of her identity, the meaning of what she has to offer in relationships, and how she can take better care of herself.

She considers Joe's perspective, tentatively explores, then tests the implications of holding them and can see how many old beliefs and behaviors link in (she is a great client!) She carefully tests the ideas in her life and checks the results against Joe's ideas.

Over time she doesn't wholesale adopt his ideas but learns to make distinctions about when her old strategies (or modifications of her old strengths) fit her requirements and when she can effectively open up to a new relationship with her world.

Her change is to some fundamental beliefs, but is not massive. Over time there could be more change, but it may not be necessary. She is not a different person, but she tweaked her way of relating that will help her. She can grow with it over time.

\section{CHANGE}

She is better able to tolerate the pain and cope with challenges.

A key learning is that it can be useful to entertain other people’s feedback, consider it, experiment with it, and derive great benefit.

She has made progress and can continue to grow because she experienced:

- Trust in a man who didn’t have a negative/irresponsible agenda

- Learned another person can be competent and can help her

- One can choose the appropriate level of control for the situation

- She can better gauge hopefulness versus denial

- $\quad$ She can enjoy sharing experiences (in part through her brother)

Was the treatment was effective and appropriate? ---yes. She was given just enough to unsnag her to move on in her life. It can't remove her memories or help her mother, but her experience with therapy altered her. She can avoid being stuck in a painful cycle of intrusive memories and unsatisfying relationships. It appears she is prepared to do the next work herself.

Her diary showed her evolution from skepticism and tentativeness---“perhaps,” "apparently,” her vacillation, her attempts to test the ideas, and the slow, halting move to certainty, then the sad or anger that results, then thinking through the fallout, then her selective and more confident use of her modified beliefs and strategies.

It is clear that she defined therapy as a different context with different rules. She seems to feel she has made an adjustment to her life and relationships that will over time make her more 
Validity of Descriptive and Causal Statements about Psychotherapy Process and Outcome

A.C. Bohart, K.L. Tallman, G. Byock, \& T. Mackrill

Pragmatic Case Studies in Psychotherapy, http://pcsp.libraries.rutgers.edu

Volume 7, Module 1, Article 8, pp. 101-144, 02-28-11 [copyright by authors]

comfortable privately. (Even though it was painful at first). She can move into having more and more comfortable, satisfying relationships with others. There is still much trial and error to come.

\section{DID THERAPY CONTRIBUTE TO THE CHANGE?}

Yes. She used therapy and people outside therapy to help her unfold the important elements of her experience.

Her goals were to:

Overcome the sadness

Forgive and forget

Deal with the grudge

Reduce headache, stomach pain

Reduce intrusive memories

Move from being not open, not trusting

Cope with being too afraid of men

Deal with feeling she is wrong- "Gone to the rats"

Find a good man

"Sort things out myself"

She nudged forward to varying degrees on these goals.

Diary---She used to do her own little analysis

Differentiation successes, e.g., selective openness-as with brother, therapist, partner

Now she believes how she is feeling is a legitimate issue- as important as how others feel.

She is becoming artful in the dance of relating:

- With boyfriends --“give him space to lead, “ She decided "receiving can be a gift!” In response, he asked about her.

- Regarding her mother- she shifted from feeling "If she is happy, I am happy” to believing others have ability — She doesn’t have to do everything.

She got some comfort from therapy- she "sees the meaning in the madness"

CHANGES She modified some beliefs and began to experience painful realities:

- Her mother “damn well won’t change”

- Moved from her ambivalence being perceived as "all mixed up" to believing there are good and bad memories

- Some somatic symptoms improved, especially stomach complaint

- Shifting from tentativeness to saying the way she was treated "damn well wasn't right" 
Validity of Descriptive and Causal Statements about Psychotherapy Process and Outcome

A.C. Bohart, K.L. Tallman, G. Byock, \& T. Mackrill

Pragmatic Case Studies in Psychotherapy, http://pcsp.libraries.rutgers.edu

Volume 7, Module 1, Article 8, pp. 101-144, 02-28-11 [copyright by authors]

- She is ready to make her own family a priority (she hought she could not)

- She seeks to both love and be loved

- She can choose to independent or dependent

- Now that she could share the experience with the therapist, it is not just hers, and she can see the truth

- $\quad$ She experiences fewer of the painful memories.

- She examined the need to feel superior. She looked at adult/child relationships and accepted the role of fear involved

- She moved, through therapy, from the sluice to being able to talk and cry.

- Therapy showed her that it was worth thinking about her feelings

I believe therapy with Joe substantially contributed to changes and advanced her far enough that she has what she needs to build a better life. Joe and his approach were well suited to the client.

\section{Gayle’s Notes.}

\section{The Client's Change}

The client Jane changed during the process of therapy primarily because she demonstrates a readiness or motivation to change before she enters therapy. This conclusion does not detract from the therapist's ability but appears to be, in this case, the prerequisite for Jane's willingness to practice new behavior in and out of therapy sessions. She often “considers” Joe's suggestions and shows a willingness to try out new behavior.

She was motivated to change

- Because of headaches since childhood and not having found a physical source of the problem.

- She also wants to "forgive and accept or forget."

- Based on her statement that "her feelings take up a lot of space"

- A lack of a physical cause for her headaches (her assumption of something being “wrong with her head") troubled her.

Her desire for help motivates her, even though therapy actually ends up focusing her in directions that she did not bargain for at the beginning but learned to work on and practice (a key issue in the case is her willingness to practice) during therapy and between therapy sessions. Jane analyzes her own situation, recorded in her log and becomes more aware of her "points of view" in new ways.

Jane's attempts to be in control changed significantly, as she practiced new behavior, especially in the activity and the reflection on her date where she told the date that she was not interested. The actual carrying out of the action and her ability to reflect on how this new 
behavior felt and how it relieved some of her anxiety helped her to gain confidence to change in other ways as she continued therapy.

Jane has a tendency to "all or nothing” thinking (a sop to CBT). She's "not good at receiving care” and quickly "becomes mother-like and take responsibility” regardless of the situation at hand. Her work as a client is apparent. She begins to articulate these behaviors in therapy and in her log. She worries that, without being in control, she will be boring, and she states: "The challenge for me probably lies in trusting that other people also have abilities and, besides this, giving them the space to show them. Maybe, I don't have to do everything myself?" (J2). Since this was stated after an early session, Jane appears to be working hard at her change. Her is willing to live in a more ambiguous stage: "Suddenly I am also becoming unsure about what I bring into relationship” (J2).

Jane also states: "It's not that I think there is anything wrong with crying. It is just that I've experienced that, as I've already said, my reactions have been relatively out of proportion...." (J3). She grows in therapy, as in the J11 session she states: I think she [mother] belittles my feelings, when I sense she thinks I am overreacting, when I, for example, get sad because she drinks” (J11). Jane has constructed a braid that contains sadness, her mother's drinking, her worry about overreacting, and that crying is ok. She is pulling together many aspects of her emotional life. She no longer assumes that "the other," in this case Jane's sense that her mother thinks she is overreacting, has the answer when it comes to determining what is going on for Jane and whether or not these emotions and thoughts are "reasonable." Jane appears to be learning that her reality can be just as valid as anyone else's and that she does not need to subserve her reality to her mother's.

Jane is aware early on of her need to live in the present of relationships. She states in J1a: I think I can see I transfer [from my relationship with my mother] some of the same elements in my relationships with boyfriends. If my boyfriend is happy, I am happy.” The presence of these insights in early log entries shows Jane's decision to change.

\section{The Contribution of Therapy Toward Change}

It is more difficult to determine how therapy contributed in terms of what the therapist actually did because there are fewer log entries from Joe and therefore I am relying on his recounting of events as part of the analysis rather than his words at the time of therapy.

The use of language different from the client's own language seemed to have helped the client in the change process. Using terms such as "grief" and "point of view" as a way to differentiate Jane's and Joe's approaches seemed to have helped the client undergo the change process by learning new language while practicing new behavior.

Therapy also helped in the shift from Jane's “forgive, accept or forget” approach to Joe's term grieving and letting go of a need to control approach. This shift allows for a change in her self-acceptance and especially in developing a sense of agency. The change in anxiety level 
Validity of Descriptive and Causal Statements about Psychotherapy Process and Outcome

A.C. Bohart, K.L. Tallman, G. Byock, \& T. Mackrill

Pragmatic Case Studies in Psychotherapy, http://pcsp.libraries.rutgers.edu

Volume 7, Module 1, Article 8, pp. 101-144, 02-28-11 [copyright by authors]

appears to help her sleep better and allows traumatic memories to emerge and be exposed to her reflection and reintegration into herself. She changes and accepts a self able to cope differently.

Jane changed her position from being "beyond help" to gaining agency for her own change process ("I am not a hopeless case" as noted in her $5^{\text {th }} \log$. She seems to indicate that this change occurred after her first session at TUBA.

The case states that Joe "doesn't just accept this concern and start trying to put her right.” This approach facilitates the change rather than causing resistance. Although Jane is clearly steering the ship of therapy, Joe is the navigator, sitting right next to her and advising on how to proceed. This relationship seems to respect Jane's need to control and takes advantage of Joe's therapeutic skills. Jane seems comfortable with this relationship since she has made a commitment to change.

Facilitation also occurs when Joe decides to concentrate on "finding a good man, especially when he says the "I-focus" is important." At first, I was offended that he focused on an external issue of "the other" rather than promoting a sense of Jane's inner strength, since the issue seemed to me to be one of codependency. I think Joe puts too much emphasis on the "Ifocus" in contact with himself rather than Jane's need to be independent in a peer relationship. I can only conclude that Joe was using his relationship with Jane as a means for Jane to practice new behavior.

However, as a juror, I had to conclude that the result worked. Finding a good man was a tangible behavior that Joe could work with, especially with the practice behavior of telling the date the truth. Only later did Joe reveal that the larger issue for him was the behavior of adult children of alcoholics. In the sessions, he did not appear to rely on these generalizations about client behavior, although, because I do not have access to the transcripts, I cannot know that for certain.

Therapy also helped the client to change because it situated the issues in the present, whereas Jane was still operating in the past. Joe's continual insistence that Jane deal with the past and presence in the present.

The therapeutic tool of Jane's keeping a log is a critical piece to the positive therapeutic process. Jane's log provides a validation of change and a place for her to record her musings outside therapy. Because of the log, Jane is able to include validation of change from conversations with her girlfriend and her brother George.

Therapy allows Jane to begin to use other language to help her change. In a section of the case labeled "shift," is this statement: "Jane practises the point of view that she might originally have called acceptance and that Joe calls grieving....Jane, however, does not continue to use the word 'accepting' to understand her point of view. She begins to use Joe's term grief (J6a, J6). Interestingly, after the shift in point of view, there is a temporary increase in the amount of traumatic material present in Jane's consciousness. This may be connected with the fact that she now has a way of dealing with the traumatic memories.” This description of changing language 
Validity of Descriptive and Causal Statements about Psychotherapy Process and Outcome

A.C. Bohart, K.L. Tallman, G. Byock, \& T. Mackrill

Pragmatic Case Studies in Psychotherapy, http://pcsp.libraries.rutgers.edu

Volume 7, Module 1, Article 8, pp. 101-144, 02-28-11 [copyright by authors]

as a tool to bring forward issues that require attention is a benefit that Jane might not otherwise have found outside therapy.

Therapy has helped Jane come full cycle back to the headaches and addressing them as a reason for going into therapy. In J5a, she states that, in leafing through her diary (not therapy $\log$ ), she does not "see any individual incidents that might have affected my state of mind to the extent that I would have made me contact TUBA. And then again...But it is all has to do with a longer story that started way back when I started getting headaches.” The case author seems to indicate that Jane makes a connection between her life story and her lifelong headaches. The fact that Jane enters therapy because of the headaches and that she learns a great deal in therapy is great but it is still unclear what happened to the headaches_-or I missed something.

A great deal of change for Jane occurs outside the therapy session, but the fact that change occurs, to me as a juror, indicates that therapy is allowing for the connections and safety necessary for a client to embark upon change. The therapy session becomes a touchstone rather than a lifeline as safety is assumed and change is bringing positive results. Jane begins to operate in a more adult world of ambiguity with more ease. She recognizes that her emotions and behaviors have been stuck in the past. Therapy helps her to move herself into the adult present. She allows herself to be wrong, right, ambiguous, truthful in ways that she formerly though cruel, and a peer rather than a child. She can try out new behavior and see how it fits. She can practice an I-focus without too much cost, and she learns to tolerate silence without having to fill it or having to fill up other people.

This interplay between articulating herself in session, articulating herself in the log, and practicing behaviors that have come about because of these stimuli (and I see the therapy and log as stimuli), speeds up change. It's possible the changes might have occurred without therapy, but they would have taken a much longer time and may not have resulted in such a strong sense of self. Therapy was timely because Jane was ready.

Jane also learns to pause before absorbing the negative. This becomes evident in J6 (“As a rule.....after a while") where she seems to see that "changing my train of though[t] usually happens all by itself after a while." In the same session, she decides to deal with the pictures or movies that play out in her head: "Maybe it would be an idea to write the 'pictures' down, that is describe the individual occurrences and the feelings I have at the time. Maybe it would help me, getting them out of my head and down on paper. My next though[t] is that it will be quite timeconsuming. But the idea may be good? I must consider this” (J6).

One other thing that Joe does that is useful to Jane. He talks about the "past can be experienced in another way if shared...”Jane states early on, "so I know that now another person knows what I know" (J1a). This happens in the first journal entry. I would say that the entry into therapy and the positive therapeutic alliance have provided both a stepping stone and a hand to ease Jane's journey of self discovery and growth. Since I believe that a client's journey is continuous and does not "start" with therapy, I am pleased that the case author appears to greatly respect that in his statement: "the points of view therapists present are not necessarily new to clients.” 